NASACONTRACTOR REPOR T

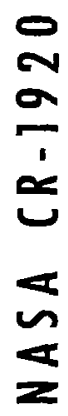

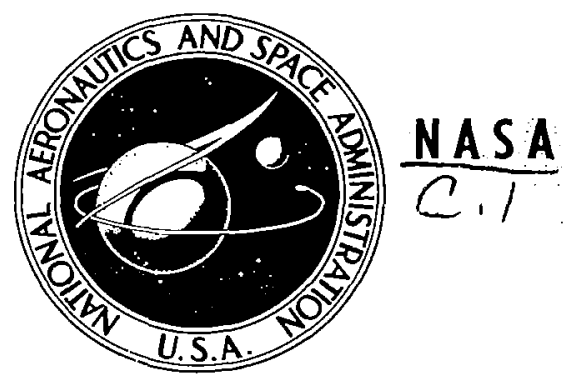

LOAN COPY: RETURPR

AFW (DOUL)

KIRTLAND AFE, M.

\title{
AN EXPERIMENTAL INVESTIGATION \\ OF BASE HEATING ON TYPICAL \\ MARS ENTRY BODY SHAPES
}

by O. L. Zappa and W. G. Reinecke
Prepared by
AVCO SYSTEMS DIVISION
Wilmington, Mass. 01887
for Langley Researcb Center

NATIONAL AERONAUTICS AND SPACE ADMINISTRATION - WASHINGTON, D. C. - NOVEMBER 1971 


$\begin{aligned} & \text { 1. Report No. } \\ & \text { NASA CR- } 1920\end{aligned}$
$\begin{aligned} & \text { 4. Title and Subtitle } \\ & \text { AN EXPERIMENTAI INVESTIGA TION OF BASE HEATING ON } \\ & \text { TYPICAL MARS ENTR Y BODY SHAPES }\end{aligned}$

\section{Author(s)}

O. L. Zappa and W. G. Reinecke

\section{Performing. Organization Name and Address}

Avco Systems Division

Wilmington, Mass. 01887

\section{Sponsoring Agency Name and Address}

National Aeronautics and Space Administration Washington, D.C. 20546
3. Recipient's Catalog No.

5. Report Date

November 1971

6. Performing Organization Code

8. Performing Organization Report No.

None

10. Work Unit No.

11. Contract or Grant No.

NAS1-9368

13. Type of Report and Period Covered

Contractor Report

14. Sponsoring Agency Code

15. Supplementary Notes

16. Abstract

Hypersonic experiments on wire supported high angle blunt cones were conducted to determine the base heating characteristics. Heating distributions were obtained for several base configurations with variations in free stream Reynolds Number and gas composition. The dependence of the heating in the base region at angle of attack was also investigated. It was found that gas composition effects can be accounted for by comparison at equal Reynolds Number. Angle of attack effects can result in either increasing or decreasing base heating depending upon the location in the base region.

\section{Key Words (Suggested by Author(s))}

Heating rate distributions

Afterbodies, high drag blunt cones

Angle of attack, gas composition

Air, carbon dioxide, mixture carbon dioxide
19. Security Casssif. (of this report)

Unclassified
20. Security Classif. (of this page)

Unclassified
18. Distribution Statement

Unclassified - Unlimited

-For sale by the National Technical Information Service, Springfield, Virginia 22151 
TABLE OF CONTENTS

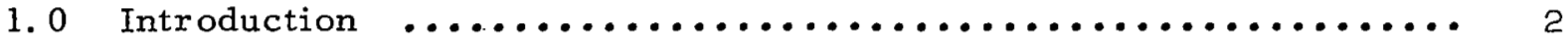

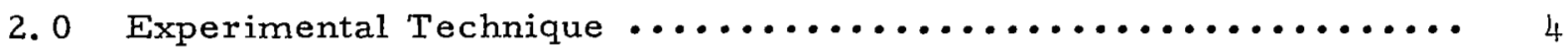

2. 1 The 20-Inch-Diameter Shock Tunnel and Instrumentation ... 4

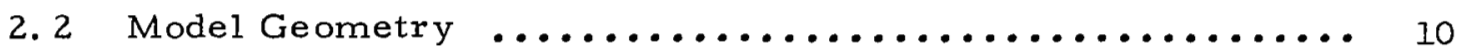

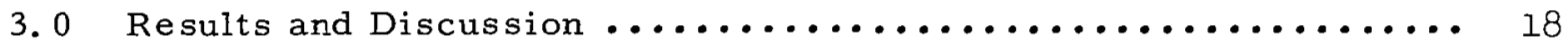

3. 1 Reference Heating Correlations $\ldots \ldots \ldots \ldots \ldots \ldots \ldots \ldots \ldots .22$

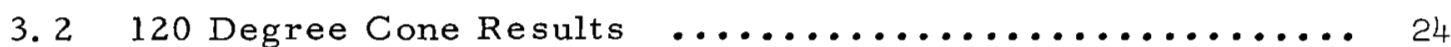

3. 3140 Degree Cone (Configuration 6) $\ldots \ldots \ldots \ldots \ldots \ldots \ldots \ldots$

4. 0 Conclusions and Recommendations $\ldots \ldots \ldots \ldots \ldots \ldots \ldots \ldots \ldots$ 


\section{ILLUSTRATIONS}

Figure

Page

1

Tunnel

Reservoir pressure trace $\ldots \ldots \ldots \ldots \ldots \ldots \ldots \ldots \ldots \ldots \ldots \ldots$

3

Heat flux history ........................ 9

4

Calibration circuit ....................... 11

5

Model schematic ......................... 12

6

Photograph of mode1

7 a, b, c Test Model Support System

Correlation of Base Pressure with Experimental Data ... 25

Base Heating, Configuration $2, \mathrm{R} / \mathrm{R}_{\mathrm{B}}=0 \ldots \ldots \ldots \ldots . \ldots 28$

Base Heating, Configuration $2, R / R_{B}=4$

Base Heating, Configuration $2, R_{1} / R_{B}=.73$

30

Base Heating, Configuration $2, R / R_{B}=.92$

Base Heating, Configuration $2, R / R_{B}=.97$

Base Heating, Configuration $2, \mathrm{R} / \mathrm{R}_{\mathrm{B}}=0$, Modified

Heating Factor

Base Heating, Configuration 2, $R / R_{B}=.97$, Modified

Heating Factor

Base Heating, Configuration $4, R / R_{B}=.22$ 


\section{ILLUSTRATIONS (Concl'd)}

Figure

Page

19

Base Heating, Configuration $4, R_{1} / R_{B}=.96$

40

20

Base Heating, Configuration $6, R / R_{B}=0$

41

21

Base Heating, Configuration $6, R / R_{B}=.31$

42

22

Base Heating, Configuration $6, R / R_{B}=.58$

43

23

Base Heating, Configuration $6, R / R_{B}=.84$

44

24

Base Heating, Configuration $6, R / R_{B}=.93$ 


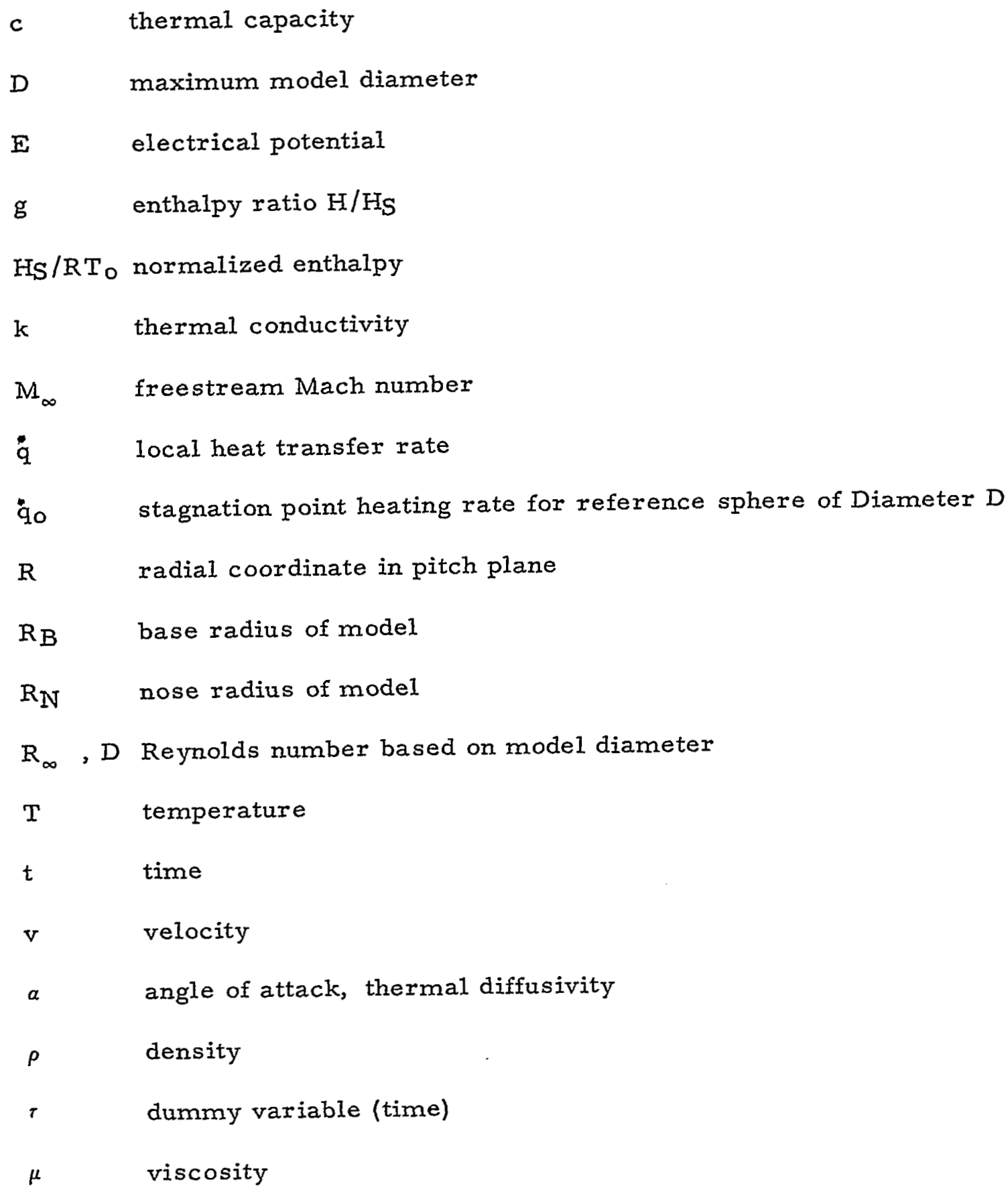


NOMENCLATURE (Concl'd)

\section{Subscripts}

$\infty$

W

e

freestream condition

conditions at the wall

boundary layer edge conditions 
NOMENCLATURE (Concl'd)

Subscripts

$\infty$

freestream condition

W

conditions at the wall

e

boundary layer edge conditions 


\title{
AN EXPERIMENTAL INVESTIGATION OF BASE HEATING ON TYPICAL MARS ENTRY BODY SHAPES
}

\author{
By
}

O. L. Zappa ${ }^{1}$ and W. G. Reinecke ${ }^{1}$

SUMMARY

Experimental studies were conducted to determine the heating on the base region of two high drag blunt cones at a Mach number of approximately 11.5 and unit Reynolds numbers of $2.5 \times 10^{6}$ and $3.0 \times 10^{5} / \mathrm{ft}$. Measurements were made on a 25 percent blunt $\left(R_{N} / R_{B}=.25\right.$ ) sixty degree (simivertex angle) cone and a 50 percent blunt seventy degree cone. The effects of angle of attack from 0 to 20 degrees were investigated as well as the effects of gas composition. Tests were performed in air and carbon dioxide as well as in an 80-20 percent by volume mixture of carbon dioxide and nitrogen. Four base geometries were tested with the sixty degree cone, while the seventy degree cone base was that of the presently configured Viking. Additional tests were conducted on a sphere to provide a normalizing reference heating. Initial tests were conducted with both a roll angle and pitch because of support mount limitations. A redesigned mounting system was fabricated and tests were subsequently conducted to determine the influence of the roll angle. The experimental data exhibit a decrease in the nondimensional heating in the base region with an increase in the Reynolds number (laminar flow). Two distinct regions exist for the sixty degree cone afterbody geometries considered: the boattail, which exhibited attached flow, and the base region with separated flow. The heating on the boattail increased with angle of attack whereas the base region heating decreased. The heating in the base region decreased from the leeward to the windward side at the outer stations. This effect diminished as the axis of symmetry was approached. Similar results were obtained for the seventy degree cone; however, no attached flow region occurred for the afterbody configuration tested.

The influence of yaw was not discernible within the scatter of the data for the Viking (seventy degree cone) configuration. However, for Configuration 4, with an extensive boattail section, the pitch plane heating data was lower than the out of pitch plane heating for regions of attached flow, indicating cross flow effects. An insufficient number of points were obtained for Configuration 2; however, there appears to be the same trend in the data.

${ }^{1}$ Senior Consulting Scientist 


\subsection{INTRODUCTION}

The consideration of probe/lander entry into the tenuous Martian atmosphere in conjunction with the Viking mission constraints and requirements has resulted in the selection of high drag shapes. The blunted cones which reflect the desired aerodynamic characteristics are such that little usable volume for packaging is available in the forebody, and as such relatively large afterbodies are required. Since in the Viking mission, the afterbody is jettisoned after fulfilling its primary functions during entry (i. e., providing protection against the aerothermal environment), its design and interfaces with the remainder of the vehicle must be as simple as possible. The need for a thermal protection system such as an insulative heat shield material may impose design problems and complexity in this respect. The heating environment, therefore, must be established in order to determine the need for and the requirements of the thermal protection system.

Of the many viscous flow problems associated with hypersonic vehicles, the separated flow region, particularly the base region, is the least understood. The separation of the boundary layer and the wake behind the vehicle have received a great deal of attention. Early theoretical solutions failed even before separation was reached and empirical relations were necessary to predict the separation characteristics (References 1 to 6 are only a few of those which have considered separation phenomena correlations).

Later investigations have been concerned with the entry observables associated with the near and far wake of ballistic missiles. These analyses have considered the base phenomena associated with slender cone flow conditions prior to separation (References 7 to 11 ).

Early analyses of the viscous flow phenomena over a planetary probe entering the Martian atmosphere (Reference 12) indicated the importance of variable entropy considerations in evaluating the forebody heating distributions at the flight conditions associated with peak laminar heating. Although these results were obtained with a sixty degree blunt cone, similar results are to be expected for the seventy degree cone; the variations, however, will be less. The effect on the base heating is twofold: in addition to variation of the flow parameters prior to base separation, the base pressure and subsequently the base external flow conditions are also sensitive to the Reynolds number. In order to assist the engineering predictions of the heating environment it is necessary to determine experimentally the heating in the base region. The present study was undertaken to provide 
heating data for the base region at conditions closely approaching flight. Effects of variations in the base geometry were considered as well as the influence of the forebody.

The correlation of the base heating is complicated by the entropy variation along the boundary layer edge which involves a coupled boundary layer flow field solution. The present data are normalized with respect to the stagnation point of a sphere of the same diameter as the blunt cones. 


\section{0 EXPERIMENTAL TECHNIQUE}

\section{1 THE 20-INCH-DIAMETER SHOCK TUNNEL AND INSTRUMENTATION}

The shock tunnel, which can be considered as a short duration blowdown wind tunnel utilizing the straight shock tube to provide a working gas of high stagnation enthalpy and pressure, has been demonstrated to be a useful tool in the investigation of aerodynamic phenomena at hypersonic speeds.

The 20-inch-diameter shock tunnel at Avco Systems Division was used for the tests described herein. The tunnel is shown in Figure 1. The highpressure, high-temperature working gas (clean air in this facility) is provided by a 1.5-inch-diameter shock tube which can be helium, combustion, or electrically driven. A 7-degree half-angle conical nozzle is attached to the end of the shock-tube-driven section and terminates in a 20-inch-diameter test section. An expansion tank is provided downstream of the test section to prevent shock reflection.

The 20-inch-diameter shock tunnel is operated in the reflected mode with room temperature driver gas (either 100 percent helium or a mixture of helium and nitrogen) at pressures up to 30,000 psia. The tailored condition is used for maximum test time. The tunnel is equipped with inter-

changeable throats to allow a range of test section Mach numbers of 11 to 18 to be attained. Tunnel performance for several driver gas combinations at 30,000 psia is as follows:

Driver Gas

100 percent Helium

90 percent Helium and 19 percent Nitrogen

60 percent Helium and 40 percent Nitrogen

Reservoir
Enthalpy
Ratio $\left(\mathrm{H} / \mathrm{RT}_{\mathrm{o}}\right)$

Test Section

Mach Number

36.0

11 to 18

16. 0

12 to 18

9. 0

12 to 18

The two test conditions for the data discussed below were a Mach number of 11.5 and a Reynolds number per foot of $3.0 \times 10^{5}$ and $2.5 \times 10^{6}$.

The tunnel instrumentation consisted of a Kistler piezoelectric pressure transducer to measure the reflected shock tunnel pressure (that is, the tunnel isentropic stagnation pressure) and a $B B \& N$ piezoelectric pressure 
FIGURE 1

A VCO 20-INCH SHOCK TUNNEL

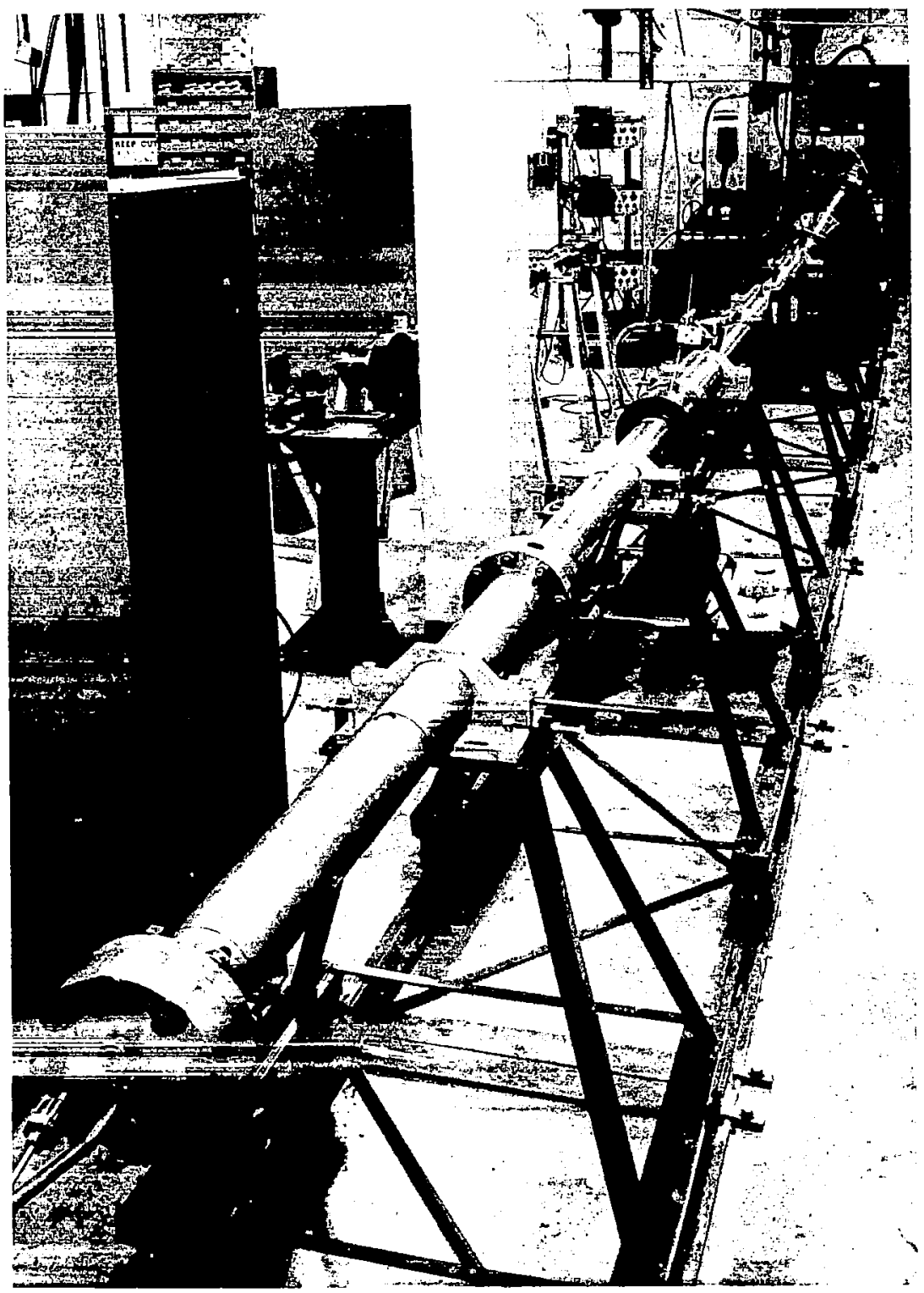


transducer to measure test section pitot pressure. A typical reservoir pressure trace as measured by the Kistler transducer is shown in Figure 2.

The heat transfer data presented herein were obtained from platinum thin film gages. The relatively short steady-state test times available in the shock tunnel make possible the measurement of heat transfer rates by sensing the transient surface temperature of the model. For the very low heat transfer rates encountered during the tests, the platinum thin film resistance thermometer is used. The heat gages are painted on the surface of a pyrex plug, contoured to fit the surface of the model under tests.

The gage may be more completely described in terms of the steps undertaken in its fabrication. Initially, two holes of 0.012-inch diameter and approximately 0. 125 inch apart are drilled in the cylindrical pyrex plug. Liquid Bright Platinum No. 05 (manufactured by Englehard Industries, Hanovia Division) is brush-painted between and into the holes. The unit is then ovenheated to $1250^{\circ} \mathrm{F}$, a temperature which results in a good bond between the pyrex and platinum. The painting and heating is repeated until five coats of platinum of the desired width have been deposited on the pyrex plug. Electrical leads are then inserted and soldered into the holes and soldered to the platinum, and the excessive solder filed off to complete the gage.

A thin film resistance thermometer measures the surface temperature of the body on which it is mounted. The theory for one dimensional heat conduction can be used to relate the surface temperature to the rate of heat transfer to the surface. The general solution for the applied heat transfer rate, assuming that the gauge thickness is negligible small is given by:

$$
\mathrm{q}(\mathrm{t})=\frac{\sqrt{\rho \mathrm{ck}}}{\pi} \frac{\partial}{\partial \mathrm{t}} \int_{0}^{t} \frac{\mathrm{T}(\lambda)}{\sqrt{t-\lambda}} \mathrm{d} \lambda
$$

which can be written as:

$$
q(t)=\frac{\sqrt{\pi \rho c k}}{2}\left[\frac{T(t)}{\sqrt{t}}+\frac{1}{\pi \sqrt{t}} \int_{0}^{t} \frac{\sqrt{\lambda T(t)}-\sqrt{t} T(\lambda)}{(t-\lambda)^{3 / 2}} d \lambda\right]
$$


FIGURE 2

RESERVOIR PRESSURE TRATE

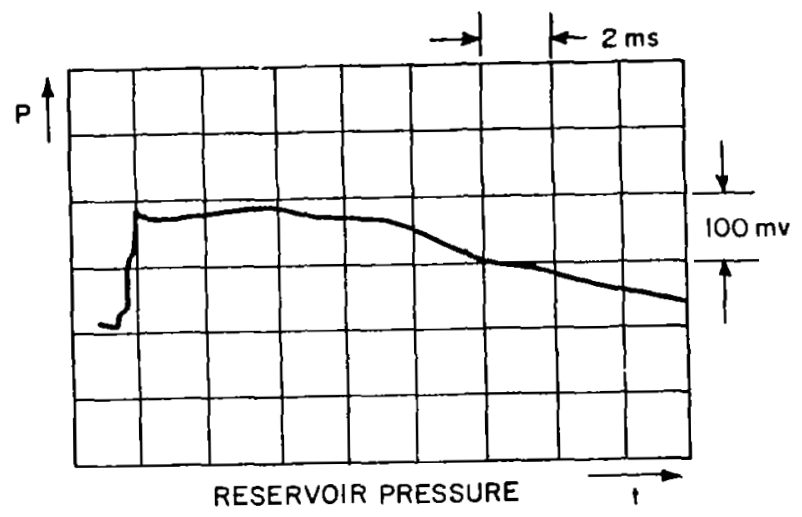


In terms of the applied and measured voltage, Equation 2 can be written as:

$$
\begin{aligned}
q(t) & =\frac{\sqrt{\rho c k}}{2 a \pi} \frac{1}{E\left(t_{0}\right)}\left[\frac{2 E(t)}{\sqrt{t}}+\int_{0}^{t} \frac{E(t)-E(\lambda)}{(t-\lambda)^{3 / 2}}\right] d \lambda \\
& =\frac{1}{k^{\prime \prime} \pi E\left(t_{0}\right)}\left[\frac{2 E(t)}{\sqrt{t}}+\int_{0}^{t} \frac{E(t)-E(\lambda)}{(t-\lambda)^{3 / 2}}\right] d \lambda
\end{aligned}
$$

where

$$
\mathrm{k}^{\prime \prime}=\frac{2 \alpha}{\sqrt{\pi \rho \mathrm{ck}}}
$$

is the calibration constant. (For a method of obtaining the calibration constant experimentally, see below).

In the foregoint equations $\rho, c$, and $k$ are the density, thermal capacity, and thermal conductivity, respectively of the pyrex gage material. The symbol $a$ is the temperature coefficient of resistivity of the platinum film. $T$ and $E$ are the temperature of the gage surface and the voltage across the film.

An equation more amenable to computational methods than Equation 3 can be obtained by using a trapezoidal type approximation. The resulting equation can be written as:

$$
q(t)=\frac{1}{k " \pi E\left(t_{0}\right)}\left[\frac{2 E(o)}{\sqrt{t}}+\frac{4}{\sqrt{h}} \sum_{m=0}^{m=n-1}\{[E(m+1)-E(m)][\sqrt{n-m}-\sqrt{n-m-1}]\}\right]
$$

where $h$ is the time interval at which the voltage is read from the oscilloscope trace; $m$ is a counter for the number of divisions of width $h$; and $n$ is a multiplier given by $\mathrm{nh}=$ time at which the heat $\operatorname{transfer}$ is required. Equation 5 has been programmed for the IBM 360 computer. The computer output is the time history of the heat flux to the thin-skinned gage in watts per square centimeter, BTU's per foot squared, or suitably nondimensionalized. A typical experimental heating rate is shown in Figure 3 in watts 
FIGURE 3

HEAT FLUX HISTORY

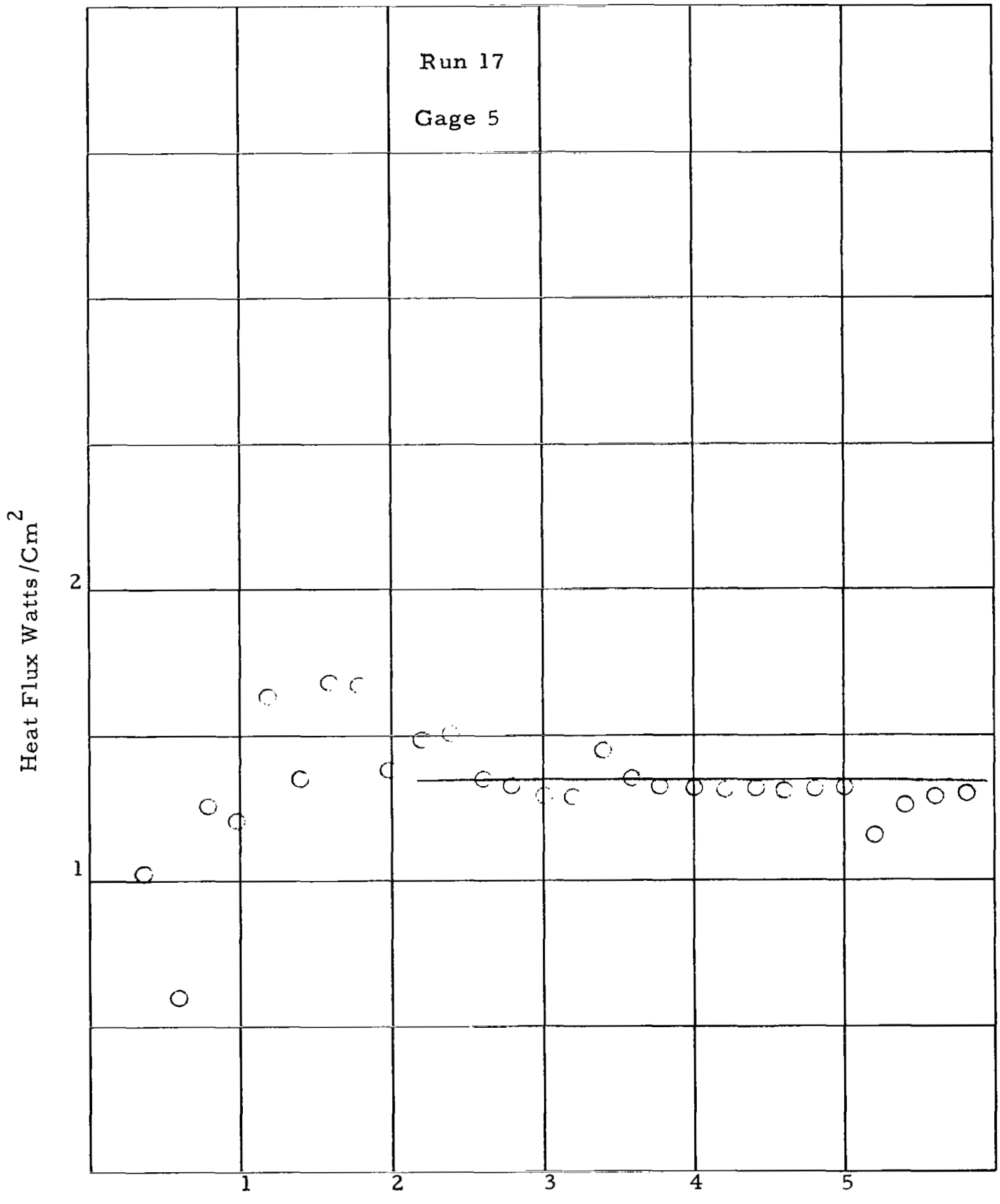

Time in Milliseconds 
per square centimeter. The initial unsteady behavior shown in the figure results from tunnel starting transients and from the errors in reading the initially small voltage variations. After about 2 milliseconds the transients subside and a steady heating rate is indicated. In the case shown in Figure 3, the steady heat flux is 1.35 watts per square centimeter.

The calibration constant, $\mathrm{k}^{\prime \prime}$ (Equation 3), is obtained from dynamic calibration of the completed heat gage by a pulse technique. The gage to be calibrated is inserted into the bridge circuit shown in Figure 4 , and the circuit is carefully balanced. A capacitor is discharged, subjecting the gage to step-function heating. The initial voltage $\left(E_{0}\right)$ and the voltage variation $(\Delta E)$ caused by the discharge are recorded on an oscilloscope, and the calibration constant is determined by means of an expression derived from Equation 3

$$
k^{\prime \prime}=\frac{A\left(R_{2}+R_{G}\right)^{4} \Delta E}{E_{o}{ }^{3} R_{2} R_{G}{ }^{2} \sqrt{t}},
$$

where $t$ represents the time over which the voltage varies by $\triangle E, A$ is the gage area, $R_{G}$ the gage resistance, $E_{o}$ the initial bridge voltage, $R_{2}$ the bridge resistance, and $\triangle E$ the change in bridge voltage. The voltage-time history $\quad \Delta E(t)$ recorded by the oscilloscope is read at four points and at least squares curve fit for $\Delta \mathrm{E}$ proportional to $\sqrt{\mathrm{t}}$ is used to compute the last factor on the equation for $k^{\prime \prime}$.

\section{2 MODEL GEOMETRY}

Six different model geometries were tested in the course of this study. The first four models were 4 inch diameter, 60 degree half-angle cones with spherical noses of $1 / 2$ inch radius and 13 degree 31 minute boattails. The fifth model was a three inch diameter sphere, and the sixth model was a 4 inch diameter, 70 degree half angle cone, also spherically blunted with a one inch radius but with a 40 degree boattail. These models, numbered 1 through 6 are sketched in profile in Figures 5a-5e. The approximate heat transfer measuring stations are also shown by the open circles in Figure 5. The precise locations of the gages, in percentage of the maximum model radius ( 2 inches) away from the rear stagnation point, are given in Table 1 .

The first four models used a common forebody made of steel. The model geometry was altered by attaching one of four different aluminum afterbodies as illustrated in Figure 5 . The model was suspended in the tunnel by 4 steel cables 0.066 inches in diameter. The cables eminated from holes in the model forebody whose locations are shown in Figure 5 by the filled 
FIGURE 4

CAIIBRA TION CIRCUIT

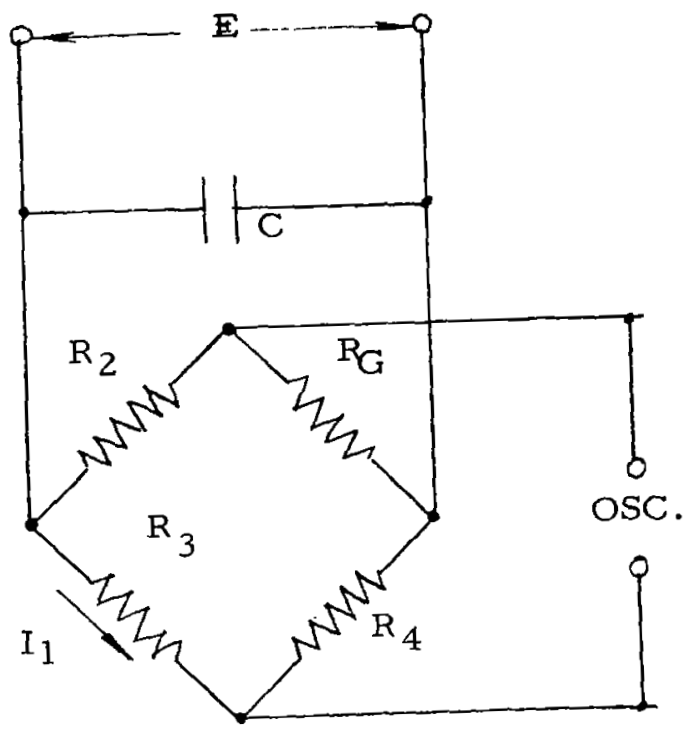


FIGURE 5

MODEL SCHEMATICS

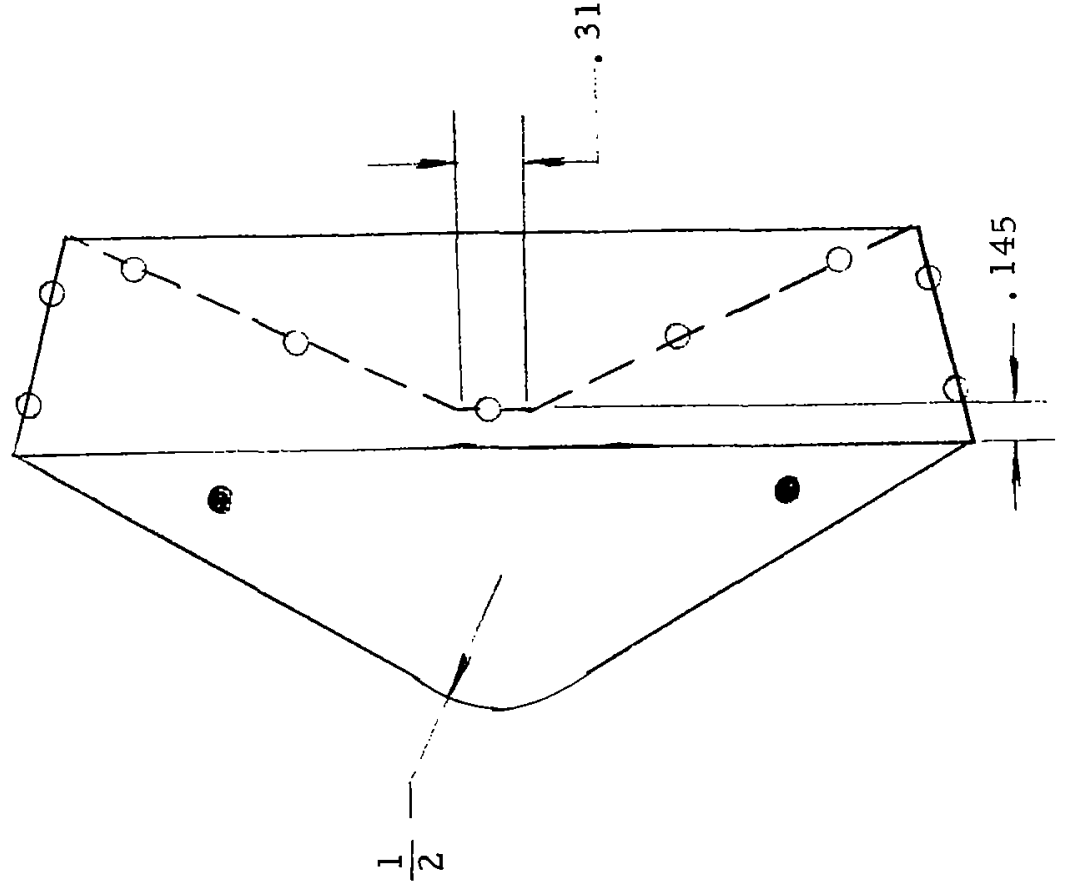

$N$
0
0
0
0

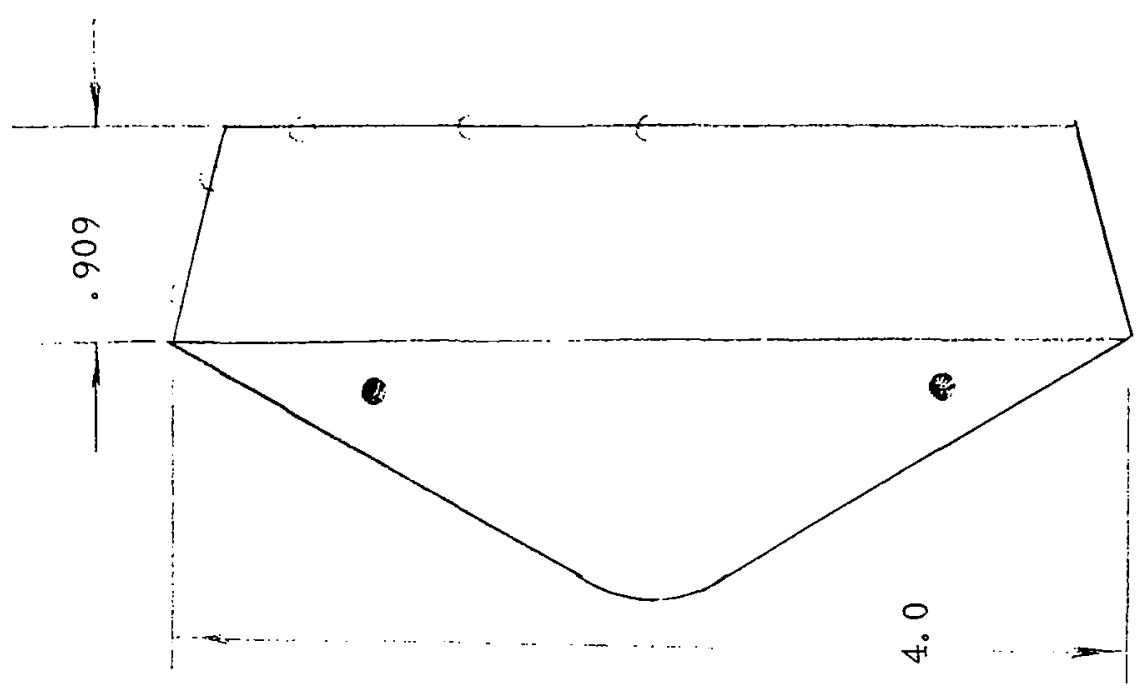

-1
$\overline{0}$
0
0
0 
FIGURE 5 Cont.

MODEL SCHEMATICS

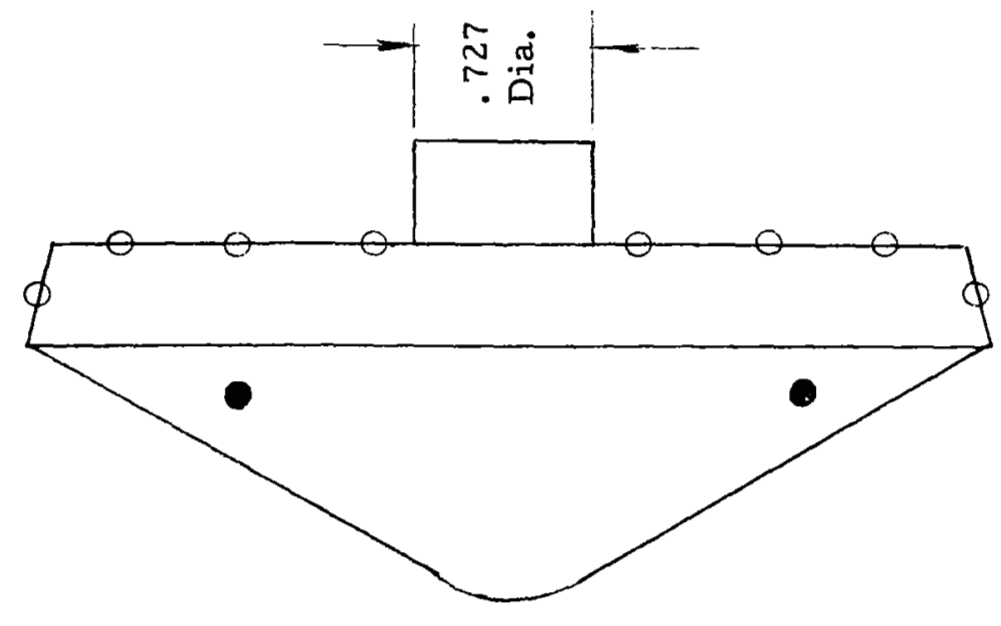

+
0
0
0
$\Sigma$
$\partial$

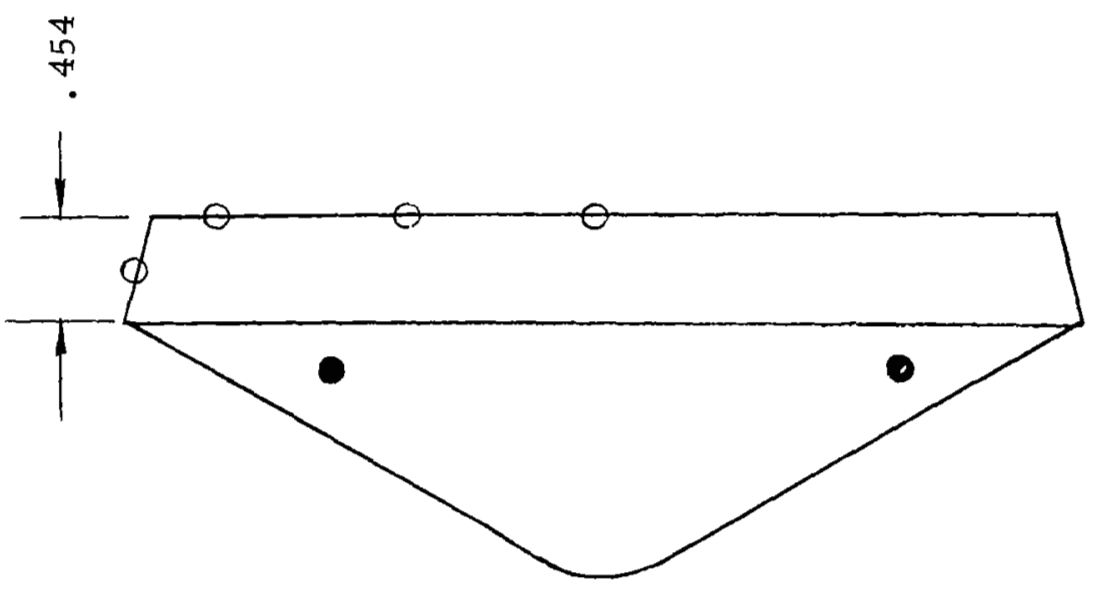

$m$
0
0
0
0
0 
FIGURE 5 Concl.

MODEL SCHEMATICS

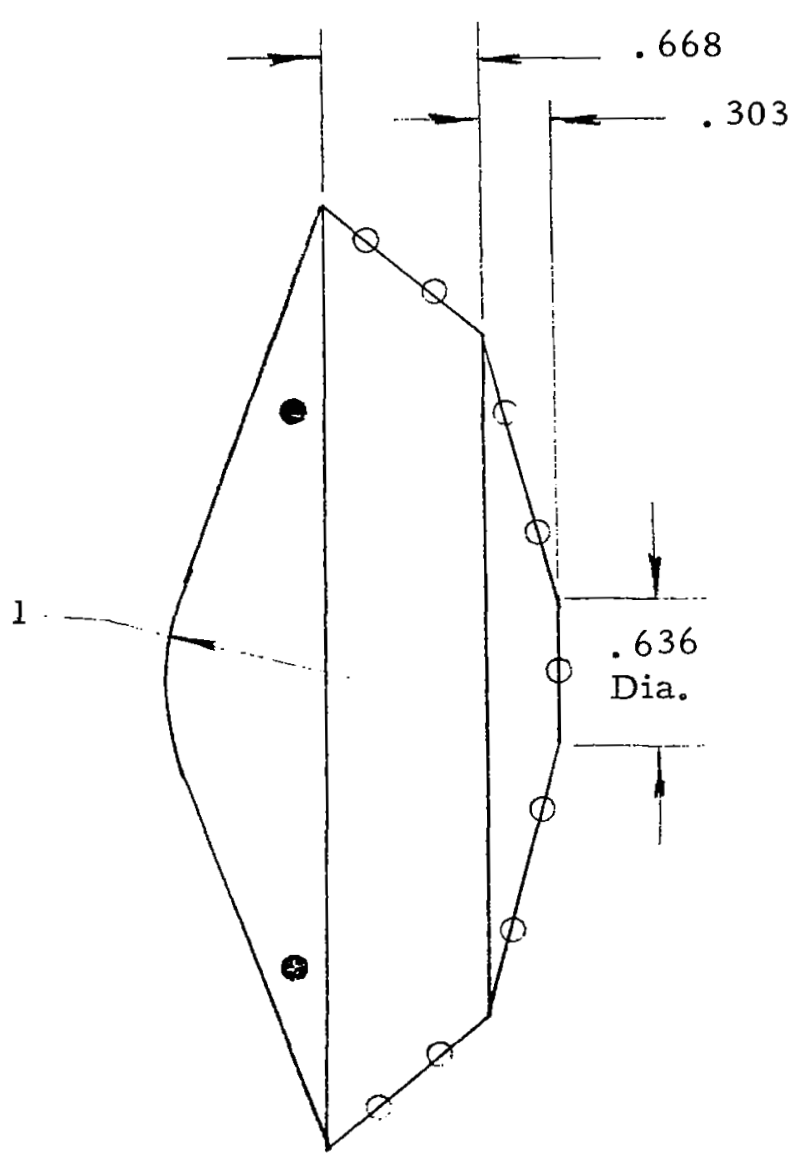

e) Model 6 
TABLE 1

\section{TABLE OF GAGE LOCATIONS}

MODEL

1

2

3

5

6
GAGE RADIAL,

LOCATION

$$
\begin{aligned}
& 0 \\
& 0.36 \\
& 0.73 \\
& 0.92 \\
& 0.97
\end{aligned}
$$

$$
\begin{gathered}
0 \\
0.4,0.4 \\
0.73,0.73 \\
0.92,0.92 \\
0.97,0.97
\end{gathered}
$$

0

0.40

0.80

0.96

$0.22,0.22$

$0.52,0.52$

$0.80,0.80$

$0.96,0.96$

0

0

$0.31,0.31$

$0.58,0.58$

$0.84,0.84$

$0.93,0.93$ 
circles. The cables were attached directly to the tunnel sidewalls. Angles of attack were obtained in the yaw plane by leaving the two vertical cables unmoved while advancing the location on the tunnel wall of the cable attachment point of one horizontal cable and moving the other attachment point aft. The cables were attached on the model at points rotated 45 degrees from the line of the thin-skinned heat transfer gages (as seen from fore or aft) to minimize any possible interference effects. A photograph of model number 6 with the suspension cables attached is shown in Figure 6.

The mounting system of Figure $7 c$ resulted in the gages being at a 45 degree roll with respect to the pitch plane. A second mounting system depicted in Figure $7 \mathrm{~b}$ was used to obtain pitch plane data. The four $3 / 32$ " diameter wire cables were attached to the forecone on one end and to adjustable supports mounted in the tunnel side-wall on the opposite end. As indicated, the heat gages were located in a plane $45^{\circ}$ to the vertical. In order, therefore, to set the angle of attack in reference to the heat gage axis, one must rotate the model about an axis normal to the heat gages, as shown in Figure 7 . This is achieved by moving supports $A_{1}$ and $A_{2}$ in a direction along the tunnel axis opposite to tiat of $B_{1}$ and $B_{2}$. The support assembly shown in Figure $7 \mathrm{a}$ is slotted so that adequate adjustment is available to obtain angles of attack from $0^{\circ}$ to $20^{\circ}$.

Model number 5 was a 3-inch-diameter sphere made of steel with a single thin-skinned heat transfer gage at the forward stagnation point. This model was mounted in the tunnel by a strut from its rear stagnation point. This model was used to measure the reference heating rate as described below.

Model number 6 (Figure 5e) was similar in construction to models 1 through 4 and was suspended from the tunnel in the same manner. 
FIGURE 6

PHOTOGRAPH OE MODEL NUMBER 6
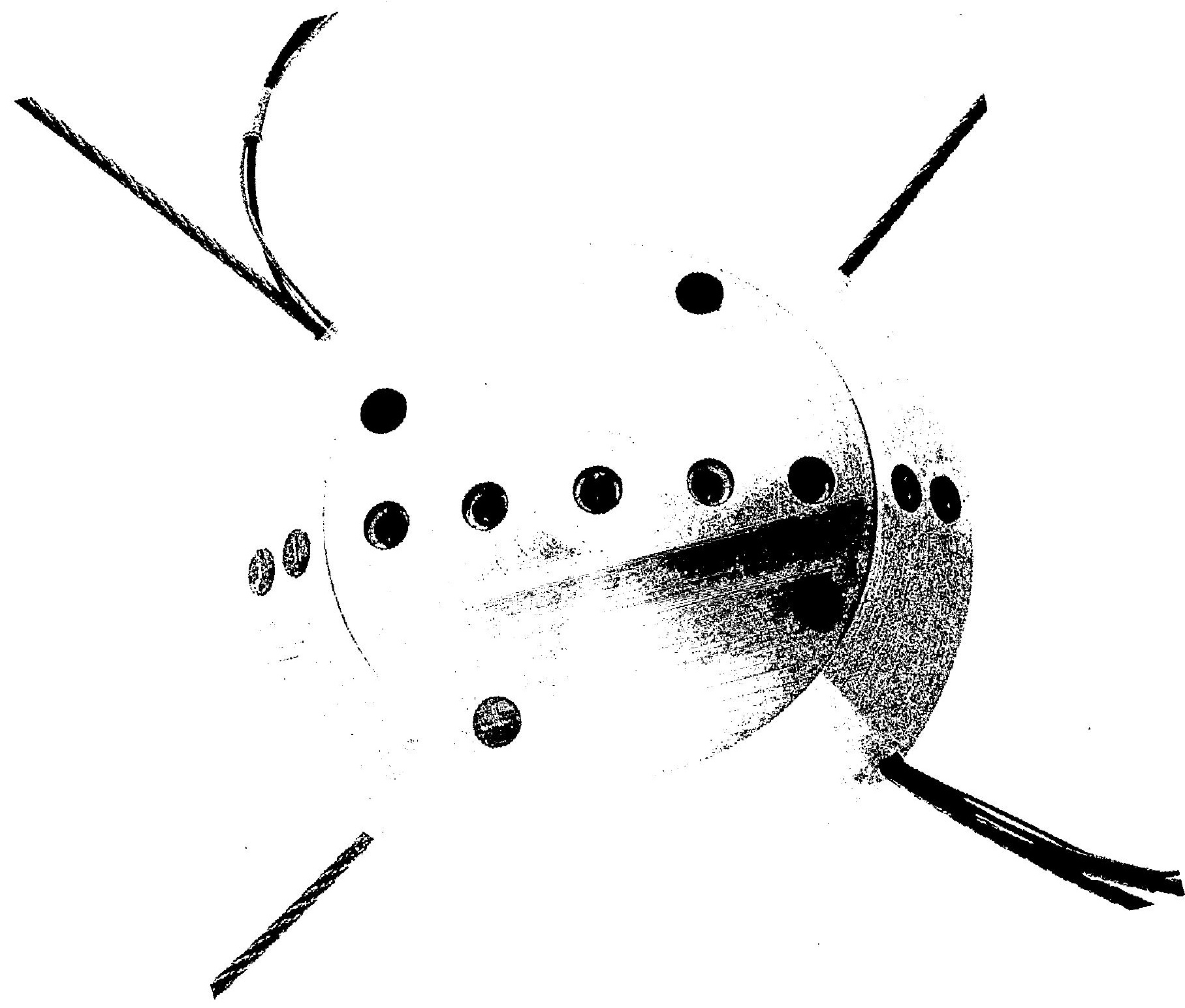


\section{0 RESULTS AND DISCUSSION}

The application of these ground test data to the evaluation of the base heating for flight conditions requires the use of suitable correlation parameters. An alternate approach is to select a basic or reference heating rate with which to normalize the data. The liklihood that the normalized heating ratio varies only slightly between test and flight makes this approach very desirable particularly in the early stages of design. Since no base pressure data were obtained, the reference heating rate was selected as the stagnation point heating for a sphere whose diameter is equal to that of the cones. This heating is readily evaluated with knowledge of the flight parameter histories. An insight into the variation of this normalized heating is obtainable by means of Reynolds number variation. This parameter is important since in addition to being critical in terms of the base pressures extant, it also is indicative of the characteristics of the flow on the forebody.

The boundary layer growth, which depends on the Reynolds number, results in boundary layer edge flow conditions which have originated from regions of decreasing shock strength on the bow shock. This results in decreasing entropy along the boundary layer edge such that the local density and velocity are higher than in the absence of the entropy gradient. (The pressure distribution will remain relatively constant as long as the sonic point is situated at the maximum diameter). The heating distribution is, therefore, altered and heating rates occur which are higher than those associated with normal shock entropy conditions.

An alternate reference heating rate was considered which considered these effects (variable entropy and base pressure). Correlations of the base pressure that were available required an extrapolation to lower Mach numbers. The two reference heating rates are discussed below. The above effects were more noticeable for the 120 degree cone since the larger nose radius and blunter cone angle resulted in a flatter shock wave for the 140 degree cone.

The initial test results indicated an inconsistency in the data. In addition the schlieren results indicated the possibility that the support system (Figure 7c) shocks interacted with the separated base flow. The problem was resolved by eliminating the support ring assembly and mounting directly to the tunnel walls. A two wire support system was used only for preliminary runs to provide visual evidence of adequate flow conditions prior to using the four wire support system used throughout the tests. In the four wire configuration the schlieren windows were replaced by a pair of plates which, in addition to anchoring the two additional wires, provided a means for varying the angle of attack. 
FIGURE $7 a$

MODEL SUPPORT ASSEMBLY

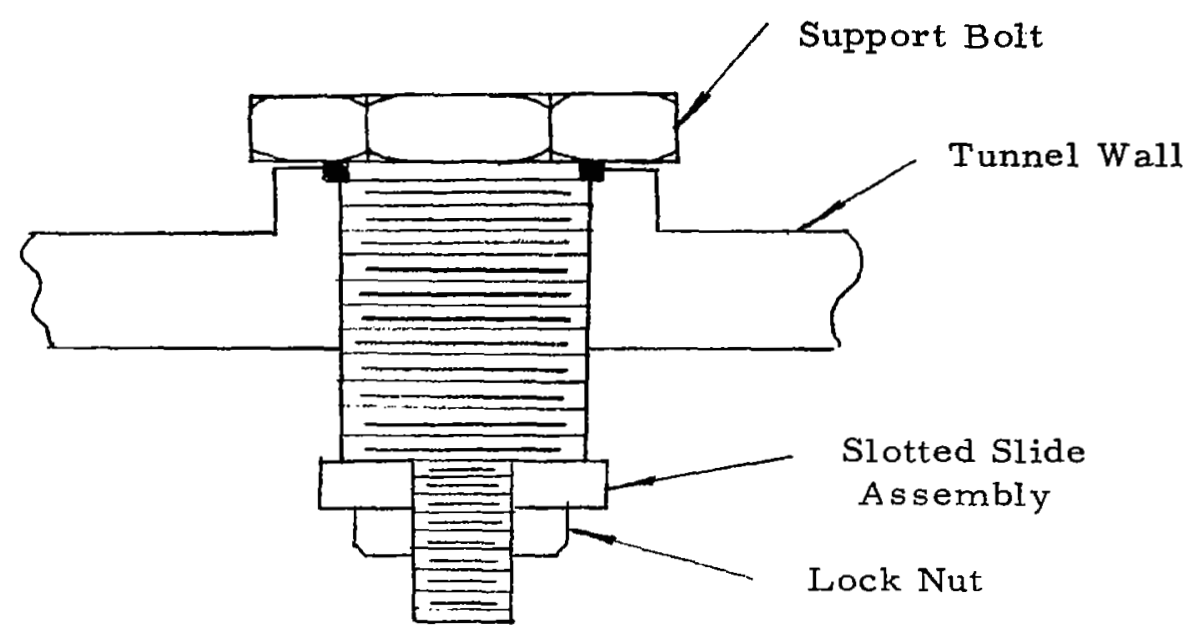

Side View

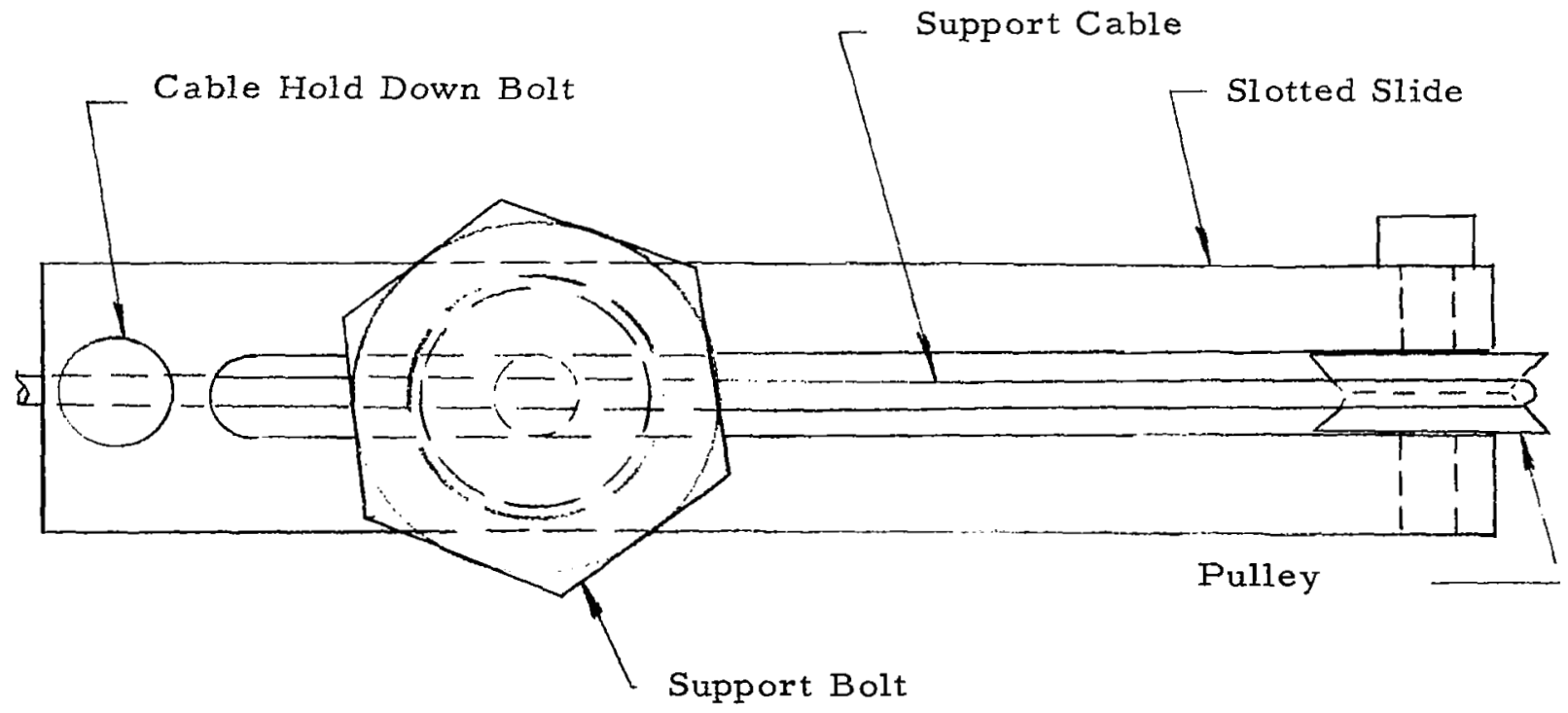

Top View 
FIGURE $7 \mathrm{~b}$

MODEL SUPPORT ASSEMBLY

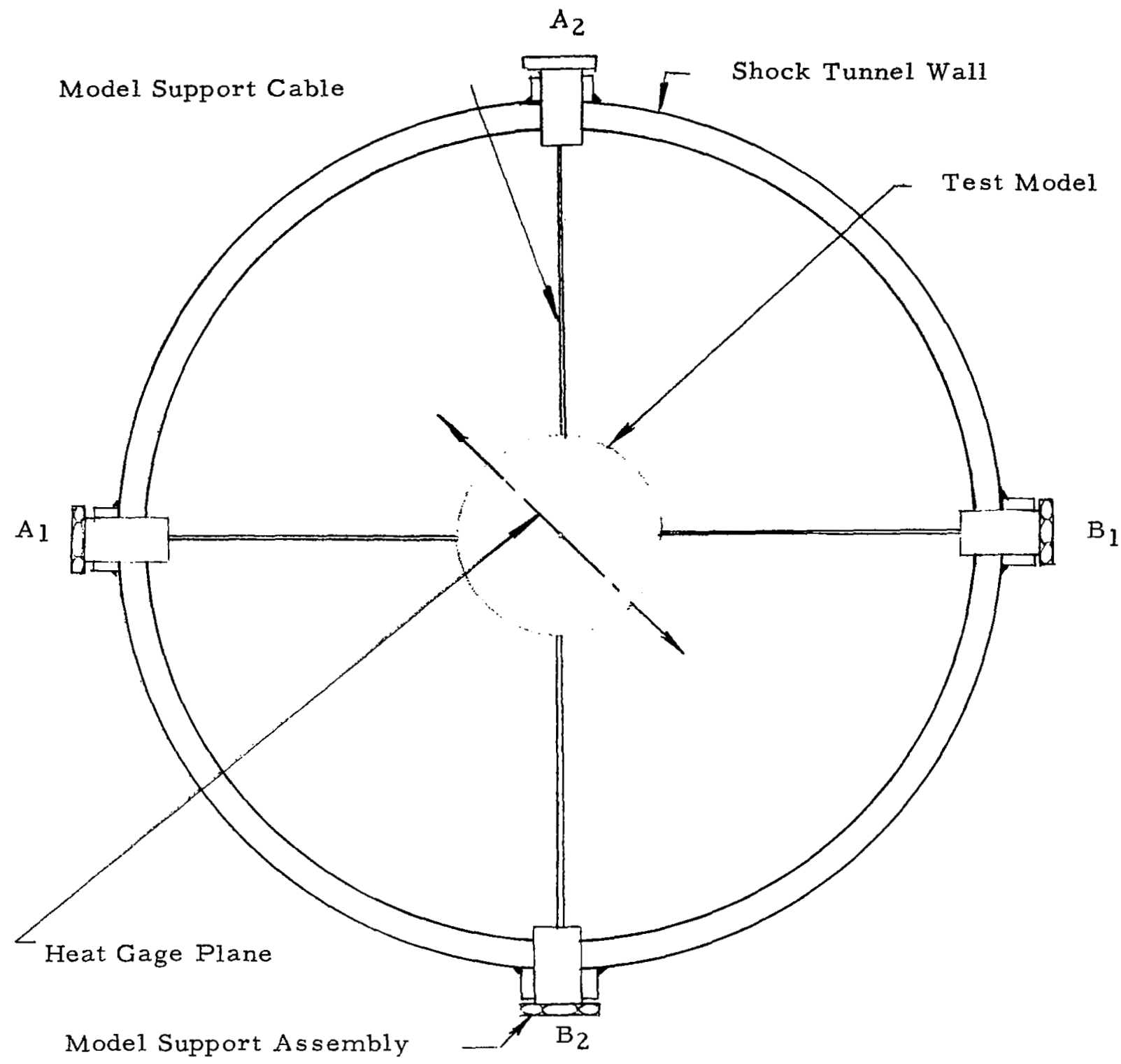


FIGURE $7 \mathrm{c}$

TEST MODEL SUPPORT SYSTEMS

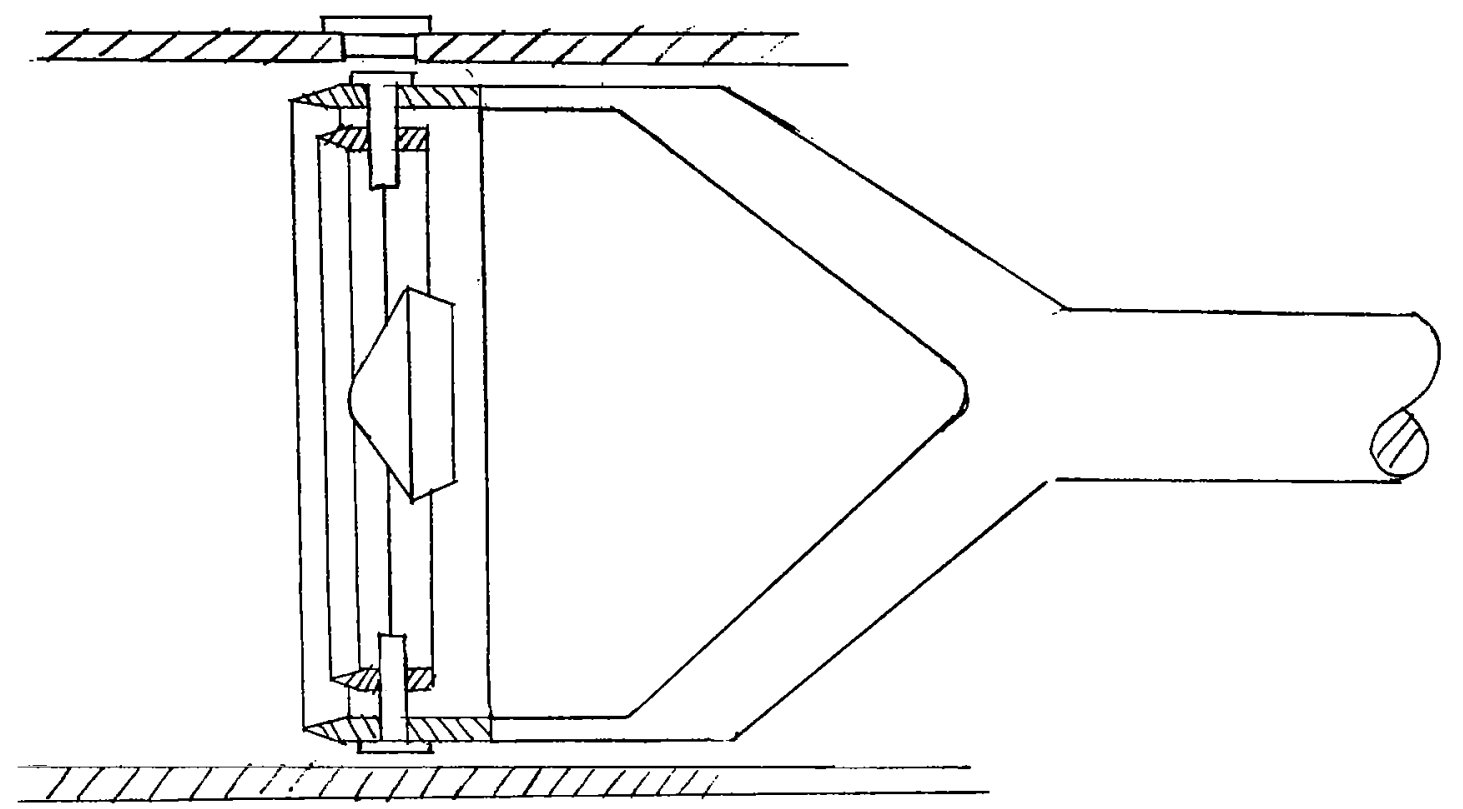

1. INITIAL

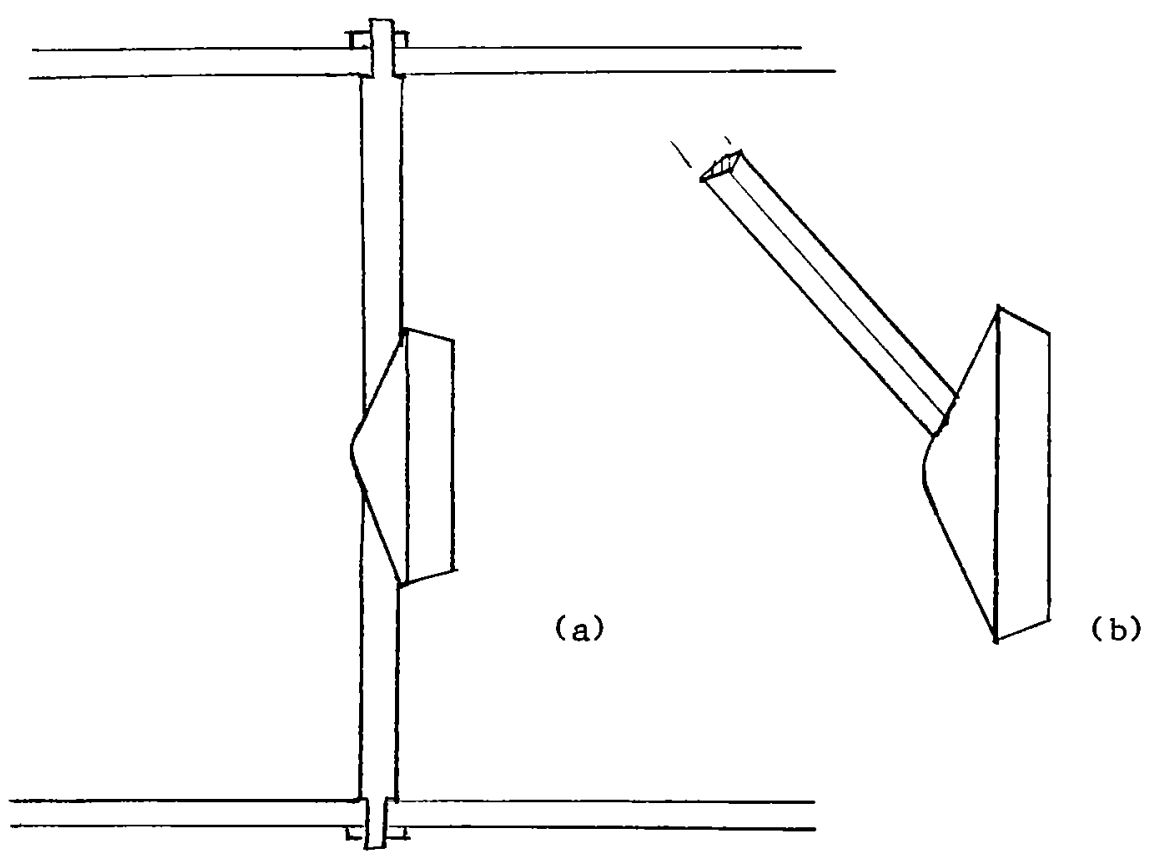

2. INTERMEDIATE 
A streamlined (double wedge) strut system was also used (see Figure 7c); however, the bow shock was displaced, since the strut was located in the sonic region of the shock layer flow. An improved forward strut arrangement is also presented, which would minimize shock shape variations and allow for smoothing out of disturbances prior to base flow separation. This system required extensive model and tunnel alteration; its consideration was, therefore, terminated.

The heat transfer gages were installed in a plane which was rotated fortyfive degrees from the cable support planes. The original ring support system (Figure 7c) was designed to provide a true pitch angle in the heat gage plane. However, the shock interactions associated with the system resulted in the selection of mounting the model directly to the walls. Only two ports were available with which to vary the location of the cables at the wall to affect an angle of attack variation; this resulted in an angle of roll between the gage plane and the pitch plane of forty-five degrees. A new mounting system was subsequently fabricated which provided a means for varying all four of the cable positions, thereby enabling the achievement of a true angle of attack in the heat transfer gage plane.

The base heating data were consistent among the shapes tested considering both the level and variations with angle of attack. The heating rates and their variations can be categorized by considering three regions, i. e., the boattail region, and the inner and outer base region. The 140 degree cone exhibited only the latter two characteristics since the boattail for that shape experienced separated flow.

The heating rates within the separated flow region of all configurations did not indicate a sensitivity to the out of pitch plane roll angle. However, the data obtained over the boattail region of Configuration 4 indicated that cross flow effects have a significant effect on the heating in this region.

\section{1 REFERENCE HEATING CORRELATIONS}

\section{1.1 Stagnation Point on a Sphere}

The data have been nondimensionalized with respect to the stagnation point heating on a sphere whose diameter is the same as that of the cone configurations. This reference heating was obtained by measurements in the shock tunnel at free stream conditions comparable to those for the cone tests. The sting mounted hemisphere model used was tested at three Reynolds numbers at a Mach number of 11.5. The data was compared with an analytical prediction method (Reference 13) the results of which are summarized in the table below. 
TABLE 2

Reynolds Number, $\frac{\rho_{\infty} \mathrm{V}_{\infty} \mathrm{D}}{\mu_{\infty}}$

$\mathrm{Nu} / \sqrt{\mathrm{Re}}$, Test

$.525, .617 \quad .667 \quad .631$

$\mathrm{Nu} / \sqrt{\mathrm{Re}}$ Fay \& Riddell (ref.13)

.557

.556

.534

$\dot{\mathrm{q}}_{\text {test }} / \dot{\mathrm{q}}_{\text {theory }}$

$.94,1.111 .20$

1. 18

The heat transfer parameter, $\mathrm{Nu} / \sqrt{\mathrm{Re}}$, is defined by

$$
\mathrm{Nu} / \sqrt{\mathrm{Re}}=\frac{\dot{\mathrm{q}}_{\mathrm{o}} \operatorname{Pr}}{\left(\mathrm{H}_{\mathrm{s}}-\mathrm{H}_{\mathrm{w}}\right) \sqrt{\rho_{\mathrm{w}} \mu_{\mathrm{w}} \frac{\mathrm{d} \mathrm{u}}{\mathrm{d} \mathrm{s}}}}
$$


The measured heating was generally higher than that which would be predicted by the reference theory and formed a 20 percent band about the theory.

\section{1.2 Reference Base Heating Calculation}

The dependence of the base pressure on the Reynolds number indicates a need for a normalizing heat transfer rate which is a function of the base pressure. A possible reference heating rate that can be used is that determined by evaluating the heating associated with the base pressure assuming an ideal expansion from the forebody.

Recent efforts (Reference 11) have evolved the base pressure both analytically and experimentally. Figure 8 presents a correlation obtained for sharp cones from the above reference. The correlation is based on - local boundary layer edge conditions prior to separation. There is excellent agreement among the data. The application of these data requires an extrapolation in order to utilize it for the blunt cones considered in the present investigation.

The edge conditions prior to separation for the 120 degree cones requires consideration of variable entropy effects to account for boundary layer growth. The mass swallowing in the boundary layer was computed (e.g. , Reference 14) iteratively and the external flow characteristics determined at the maximum diameter region. The heating prior to separation as well as the reference base heating were computed by means of the reference enthalpy method (Reference 14 and 15).

The variable entropy effects on the 140 degree cone were very small for the test conditions. Table 3, below, presents a tabulation of the reference heating rates for the two test Reynolds numbers computed by the above method. The reference base values are less sensitive to Reynolds number than the stagnation point on the sphere since the base pressure decreases with Reynolds number.

\section{2 I20 DEGREE CONE RESULTS}

\subsection{Configurations 1 and 2}

Configurations 1 and 2 data are presented together since both had the same boattail geometry. Configuration 1 had a flat base whereas configuration 2 had a conical-concave base. The configuration 1 data were obtained only at zero angle of attack. 
FIGURE 8

CORRELATION OF BASE PRESSURE WITH EXPERIMENTAL DATA

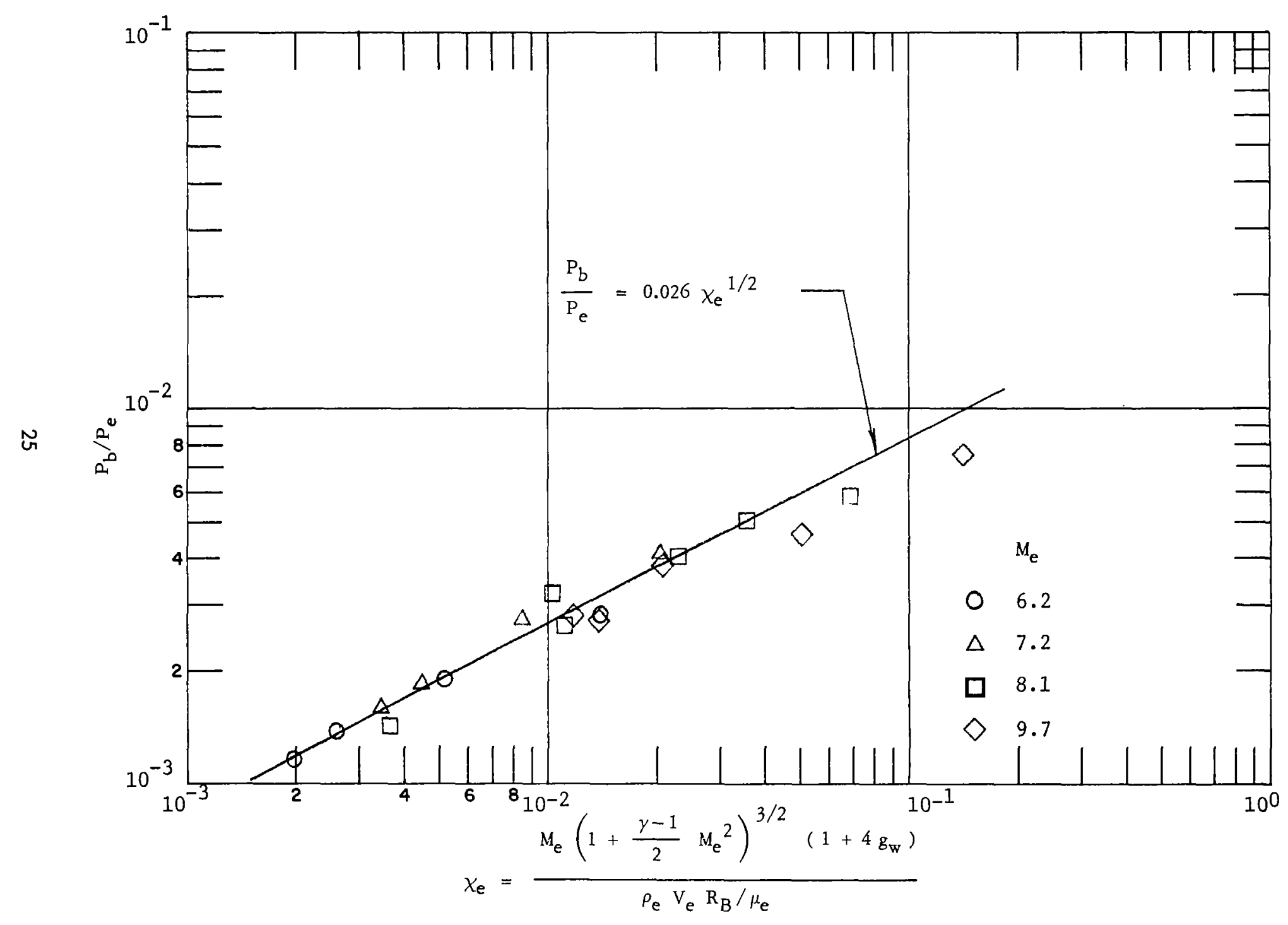




\section{TABLE 3}

\section{Reference Heating Values}

\section{$\mathrm{R} \infty, \mathrm{D}$}

Reference Stagnation Point Heating on Sphere, $R_{N}=2$ inches (watts $/ \mathrm{cm}^{2}$ )

Reference ${ }^{B}$ ase Heating, $R_{B}=2$ inches (watts $/ \mathrm{cm}^{2}$ ) $\underline{1 \times 10^{5}} .83 \times 10^{6}$

22.5

77

1.2

2.7 
Figures 9 through 13 present the results sequentially for stations proceeding out radially from the axis of symmetry. The results indicate that the afterbody can be divided into three regions, i. e., the boattail and the inner and outer base region. The inner base data (all the data have been normalized by means of the reference sphere stagnation point heating) indicated a reduced heating at angle of attack for both windward and leeward stations (see Figures 9 and 10) whereas the outer stations (see Figure 11) exhibited higher heating for the leeward station. The boattail region exhibited attached flow type heating variations (Figures 12 and 13).

It would be expected that the concave base would experience reduced heating at the axis of symmetry similar to concave nose shapes in stagnation point flow. Figure 9 indicates this is possible for the base flow stagnation point; however, this is not apparent for the other base stations. There was very little difference in boattail heating between the two configurations.

Only one test was conducted for the configuration 2 shape at a true angle of attack of ten degrees (low pressure). The results did not indicate a significant difference or trend in the heating between the out of pitch and true pitch data.

The $\mathrm{CO}_{2}$ gas mixtures resulted in Reynolds numbers similar to the high Reynolds number for air is shown in Table 4. The data with the $\mathrm{CO}_{2}$ mixtures (the flagged symbols in the Figures) were consistent with the high Reynolds number air results.

Utilizing the base reference heating rates in lieu of the sphere stagnation point heating for normalizing the data results in a reduction in the spread of the data between the two Reynolds numbers. The base region data (Figure 14) agree reasonably well with this correlation. The level of heating is less than would be predicted by Chapman (Reference 16). There is a Reynolds number effect for the boattail (Figure 15) which is unaccounted for by the base pressure dependency discussed above. Viscous interaction may be a possible source of these results.

\subsection{Configurations 3 and 4}

These configurations had reduced boattail lengths with flat bases. Configuration 4 had in addition an appendage at the axis of symmetry (see Figure 5d). Configuration 3 data were obtained only at zero angle of attack. 


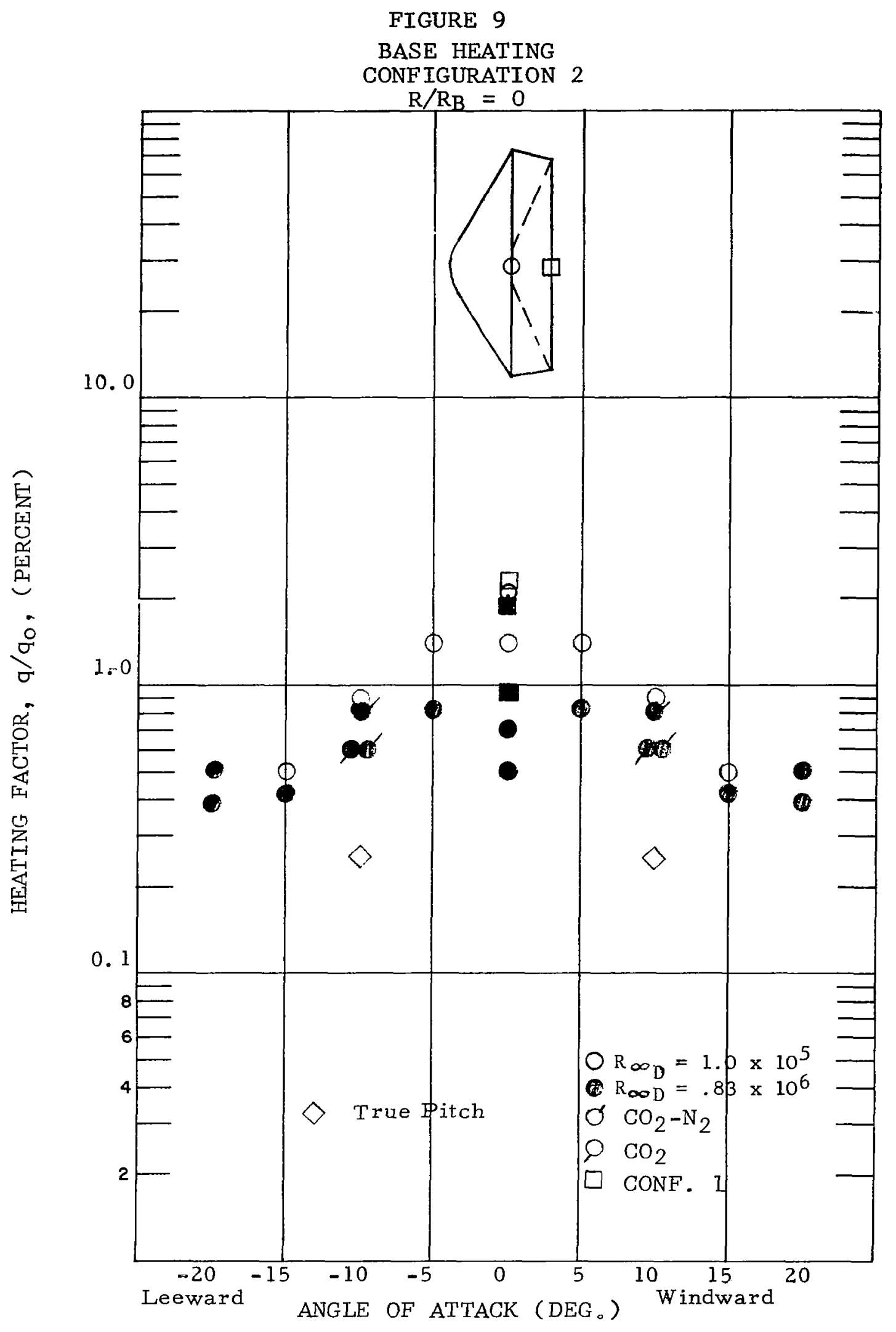




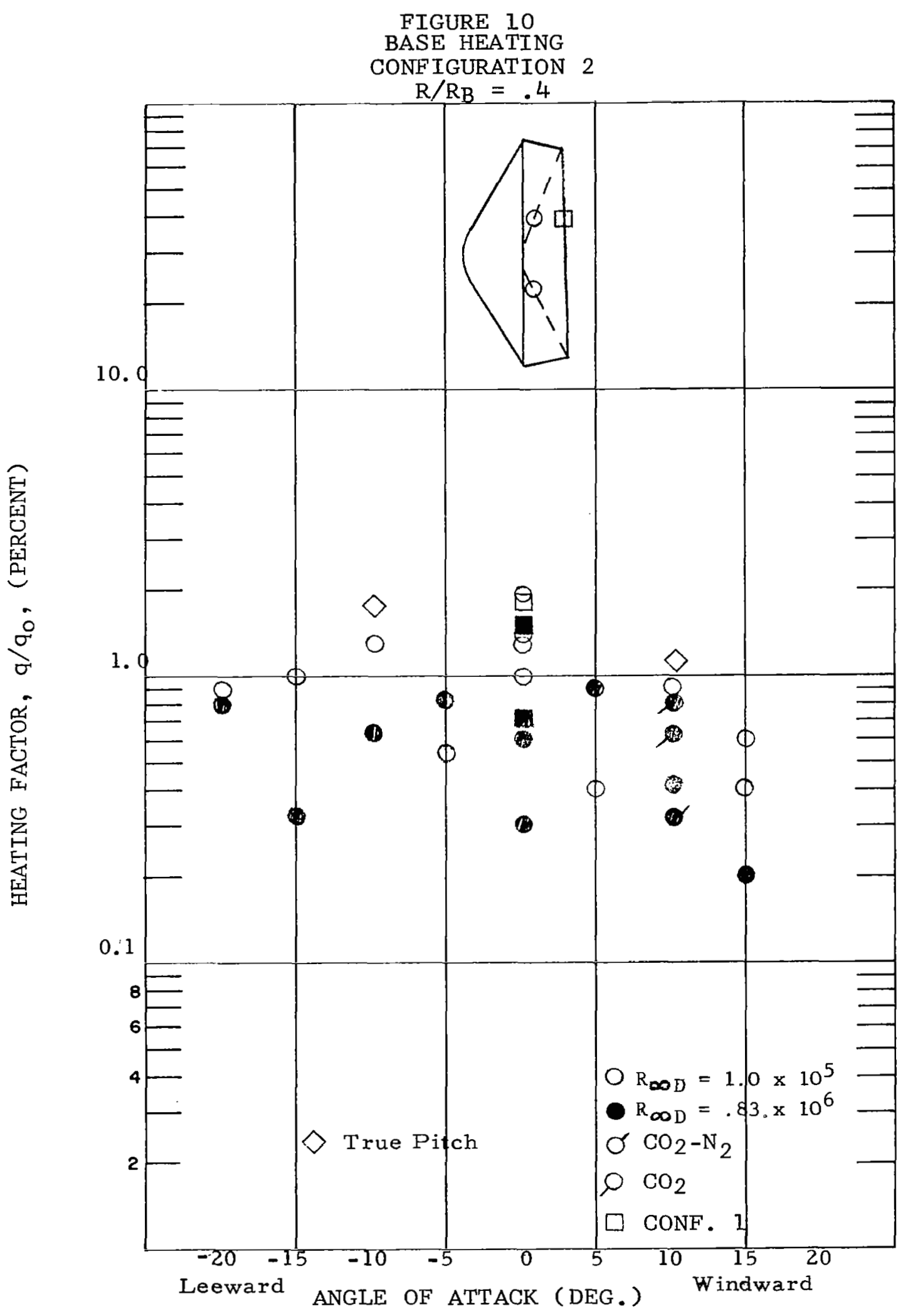




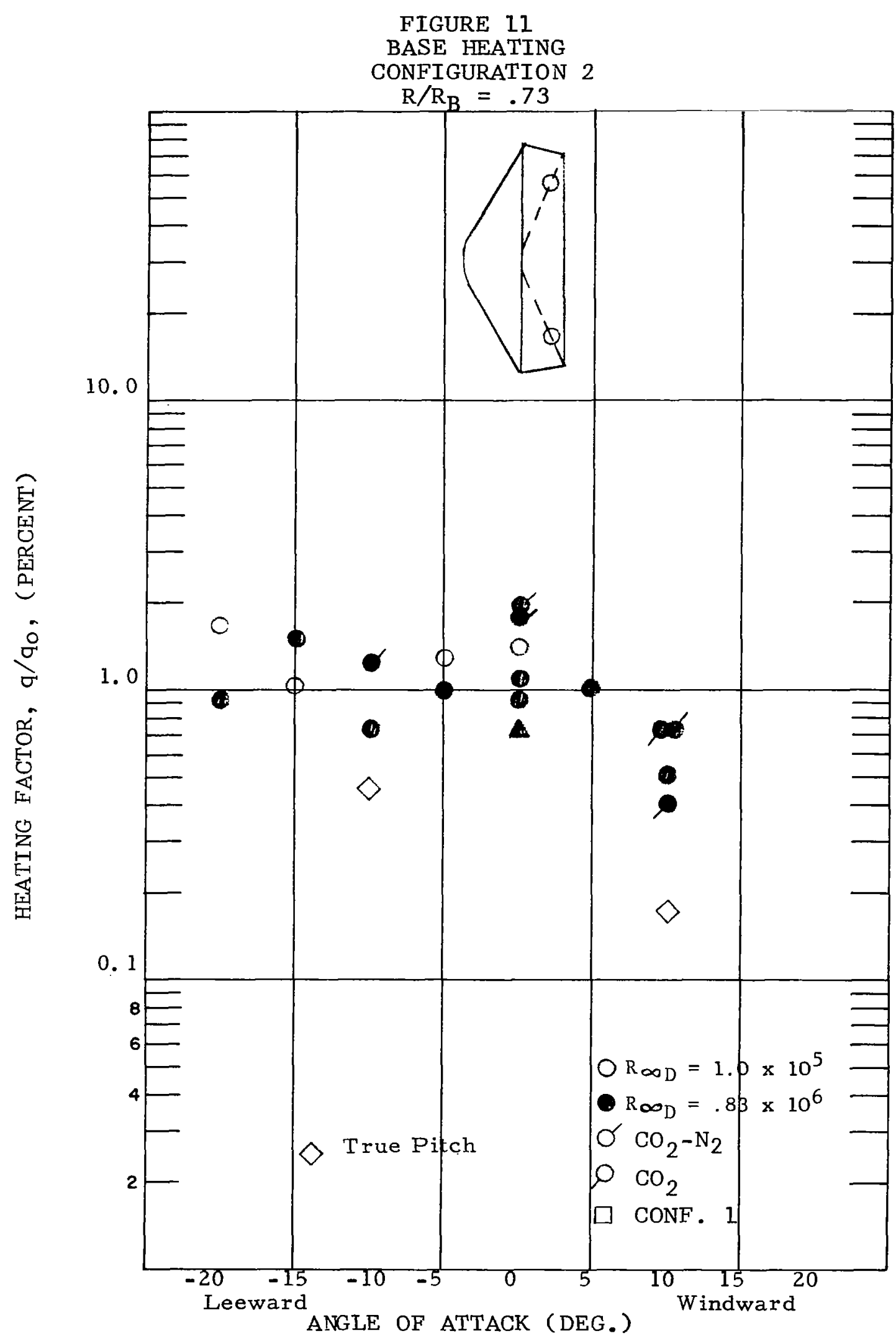




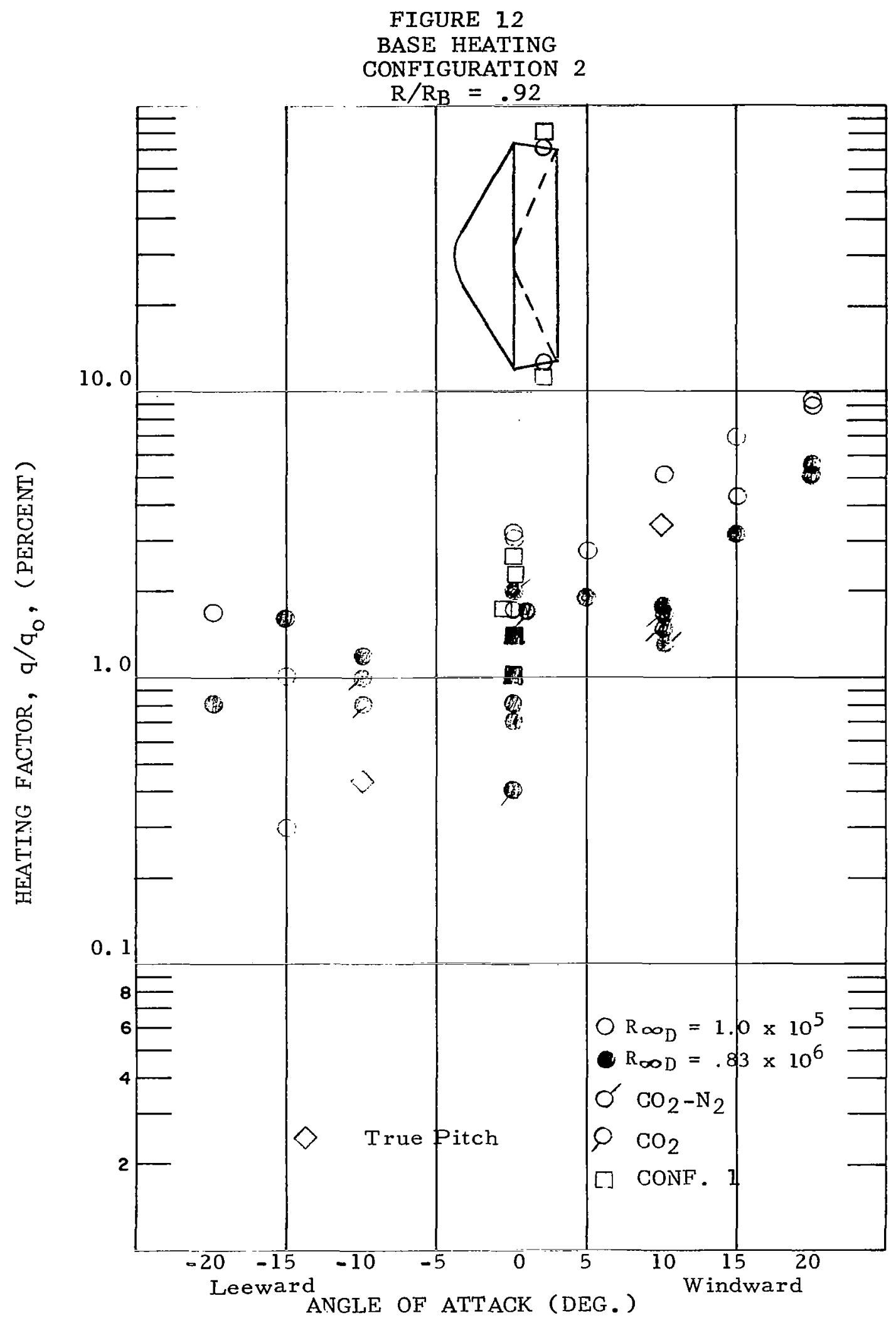




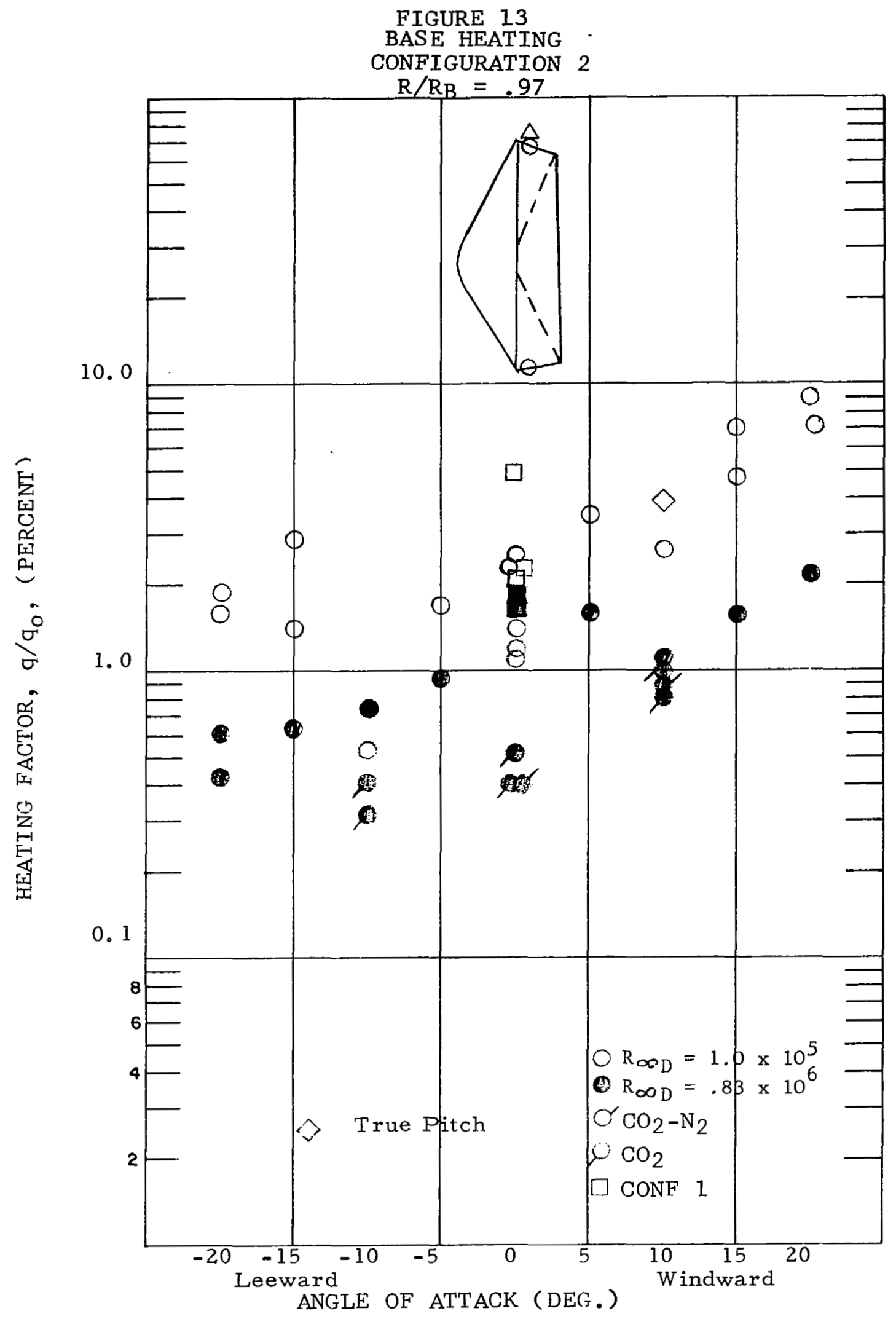


TABLE 4

TEST MIXTURE

Air

Carbon Dioxide

$80 \mathrm{CO}_{2} / 20 \mathrm{~N}_{2}$
FREE STREAM REYNOLDS NUMBER FOOT

$2.5 \times 10^{6}$

1. $74 \times 10^{6}$

$1.9 \times 10^{6}$ 
FIGURE 14

BASE HEATING

CONEIGURATION 2

$\mathrm{R} / \mathrm{R}_{\mathrm{B}}=0$

MODIFIED FACIOR

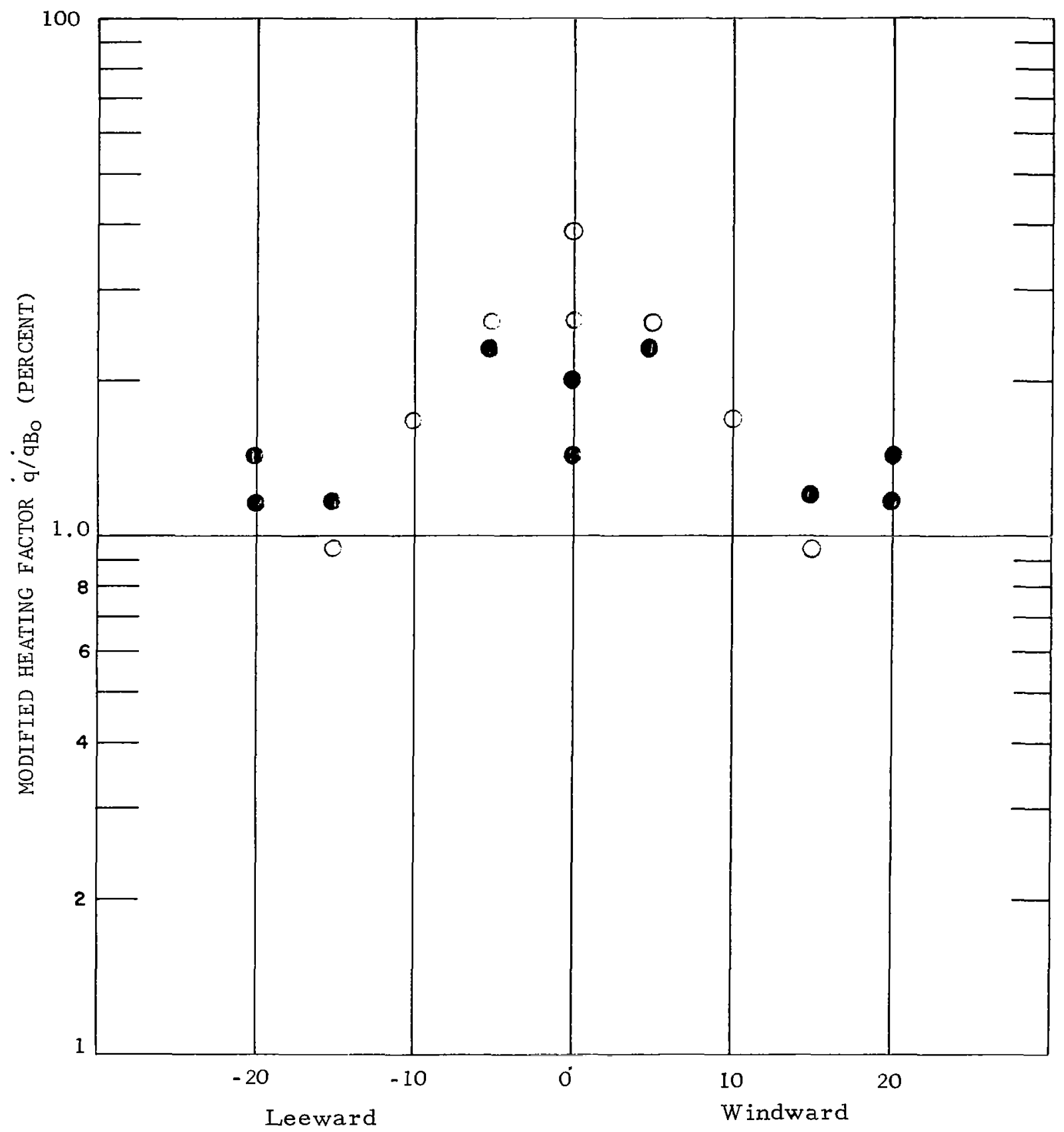

ANGLE OF ATTACK (DEGREES) 


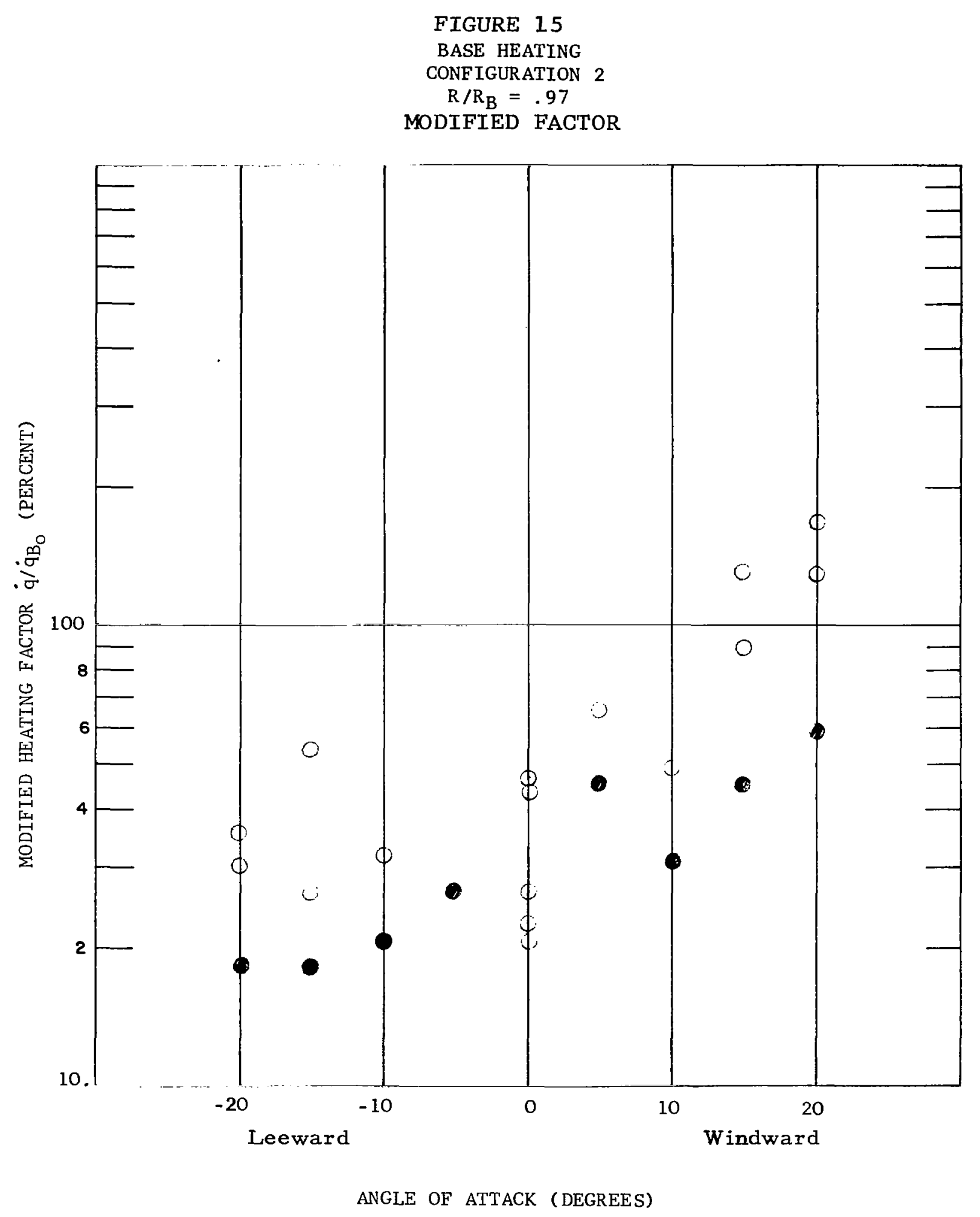


The results (see Figure 16 to 19) were substantially the same as those for configurations 1 and 2 . Within the basic regions defined above, i. e., boattail, and inner and outer base, there is no definitive statement that can be made with regard to the variation in heating between the shapes. The angle of attack variations were similar and the level of heating was the same for the configurations 3 and 4 and configurations 1 and 2 .

The pill box appendage on the configuration 4 base had no apparent effect on the base heating when compared to the configuration 3 data, although there was a slight decrease in the heating at $R / R_{B}=.52$ (Figure 17) with the appendage.

The boattail heating was consistent with the configurations 1 and 2 again indicating an attached flow type variation.

The data which were obtained out of the pitch plane were consistent with the pitch plane data (see Figures 16 to 18); however, the boattail region (Figure 19) exhibited higher heating for the out of pitch plane data. The heating was higher by a factor of two over the range of angle of attack tested. No data were obtained at zero angle of attack to affirm any cross flow effects.

\section{3140 DEGREE CONE (CONFIGURATION 6)}

The Viking configuration exhibited the base flow heating characteristic (Figures 20 through 24) similar to configurations 1 through 4, when considering the boattail as part of the base. The heating was higher on the leeward side (compare Figure 24 with Figures 11 and 18) in contrast to the windward side for the outer base region. The inner region of the Viking configuration did not exhibit the reduction in heating at angle of attack which characterized configurations 2 and 4 (Figures 9, 10, 16 and 17).

The base heating for the 140 degree cone was generally lower than the 120 degree cone when both are normalized with respect to the stagnation point on the reference sphere. In addition there was less of a Reynolds number effect for the Viking shape in contrast to the other shapes. This is to be expected since the variable entropy effects are considerably less; however, the base pressure effect should still be apparent. The 140 degree cone results agree best with the high Reynolds number 120 degree cone results. It has been estimated that at the high Reynolds number test conditions, the 120 degree cone has normal shock entropy at the maximum diameter stations.

The pitch plane and out of pitch plane data were consistent within the scatter exhibited by the data. 


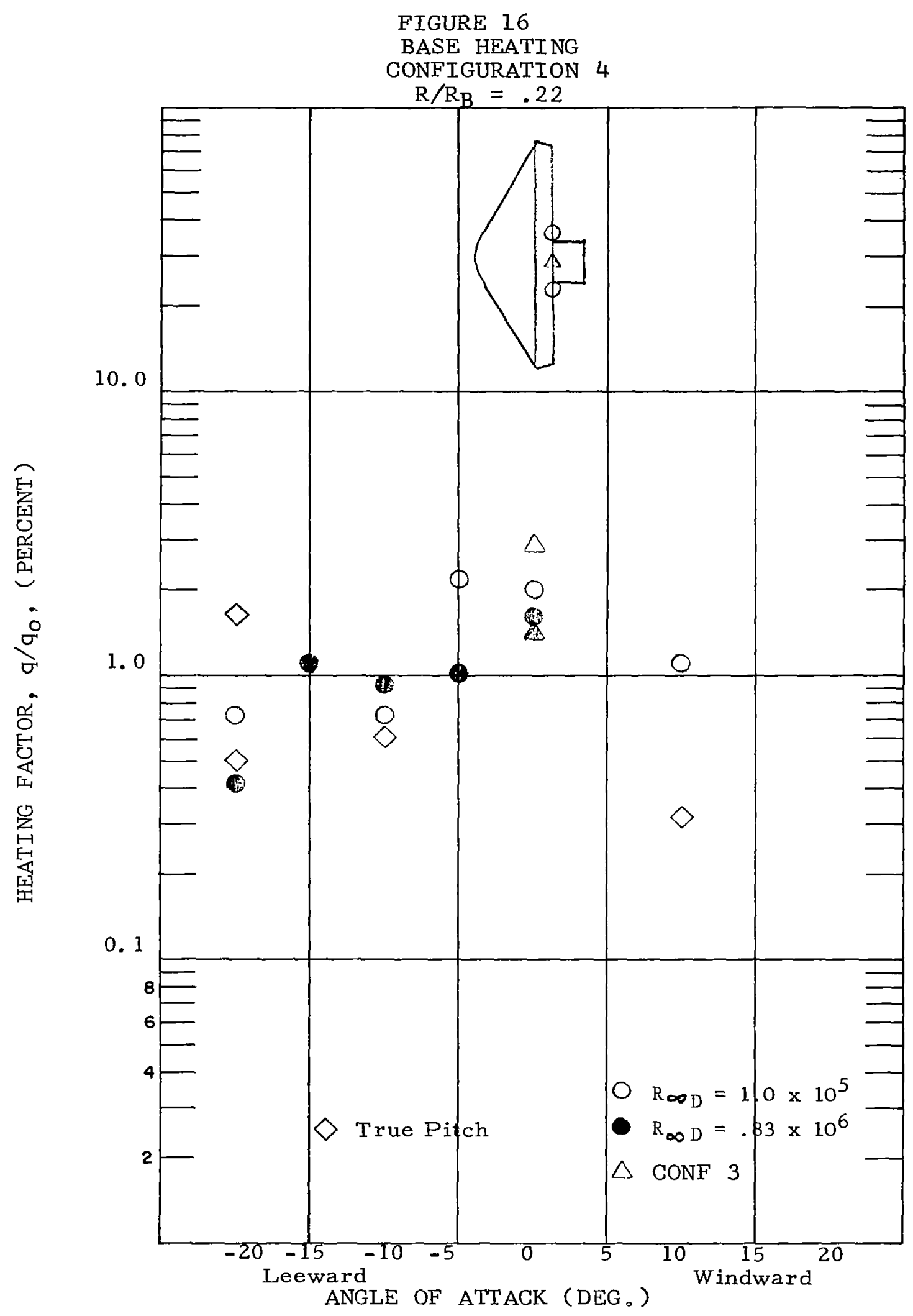




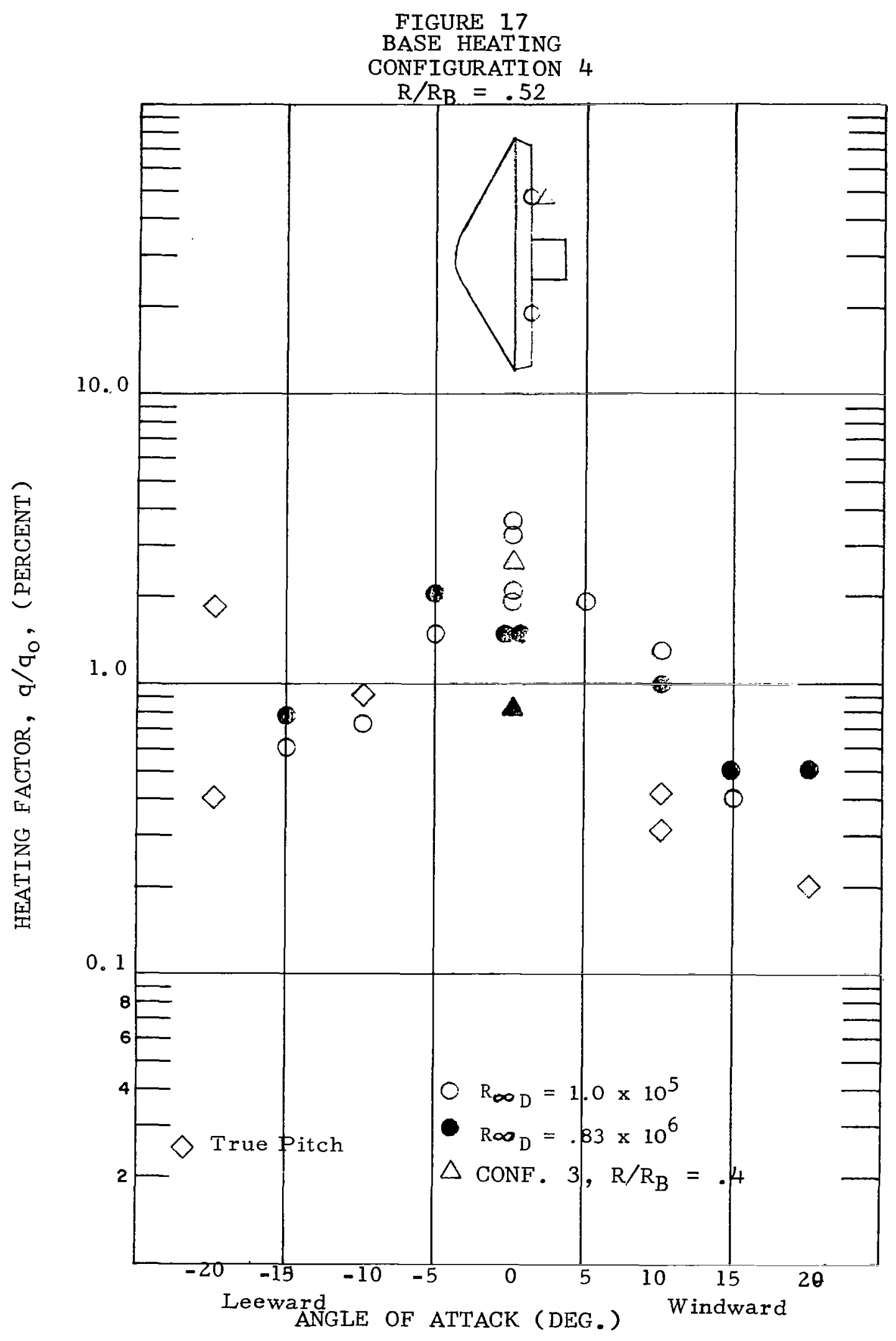




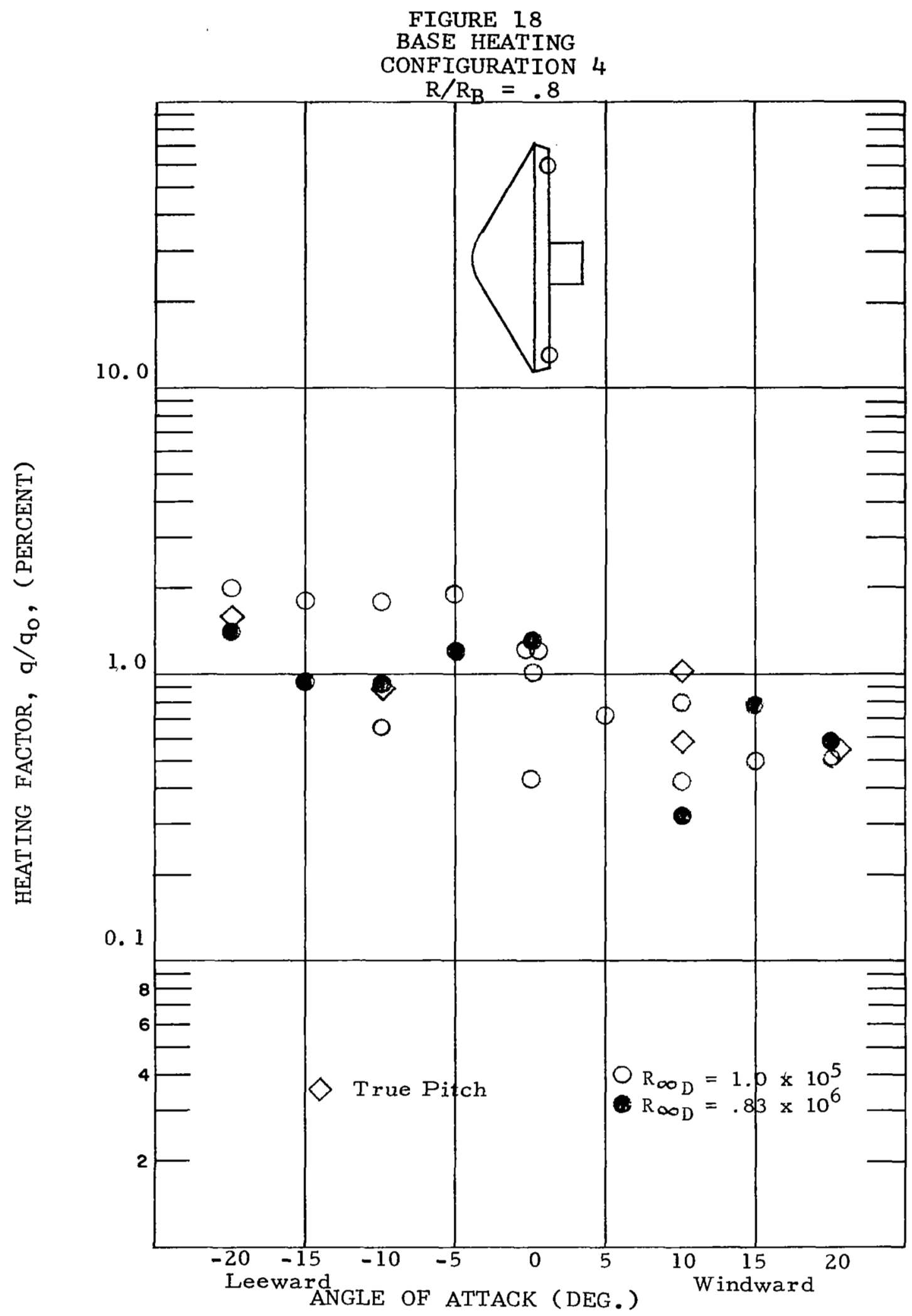




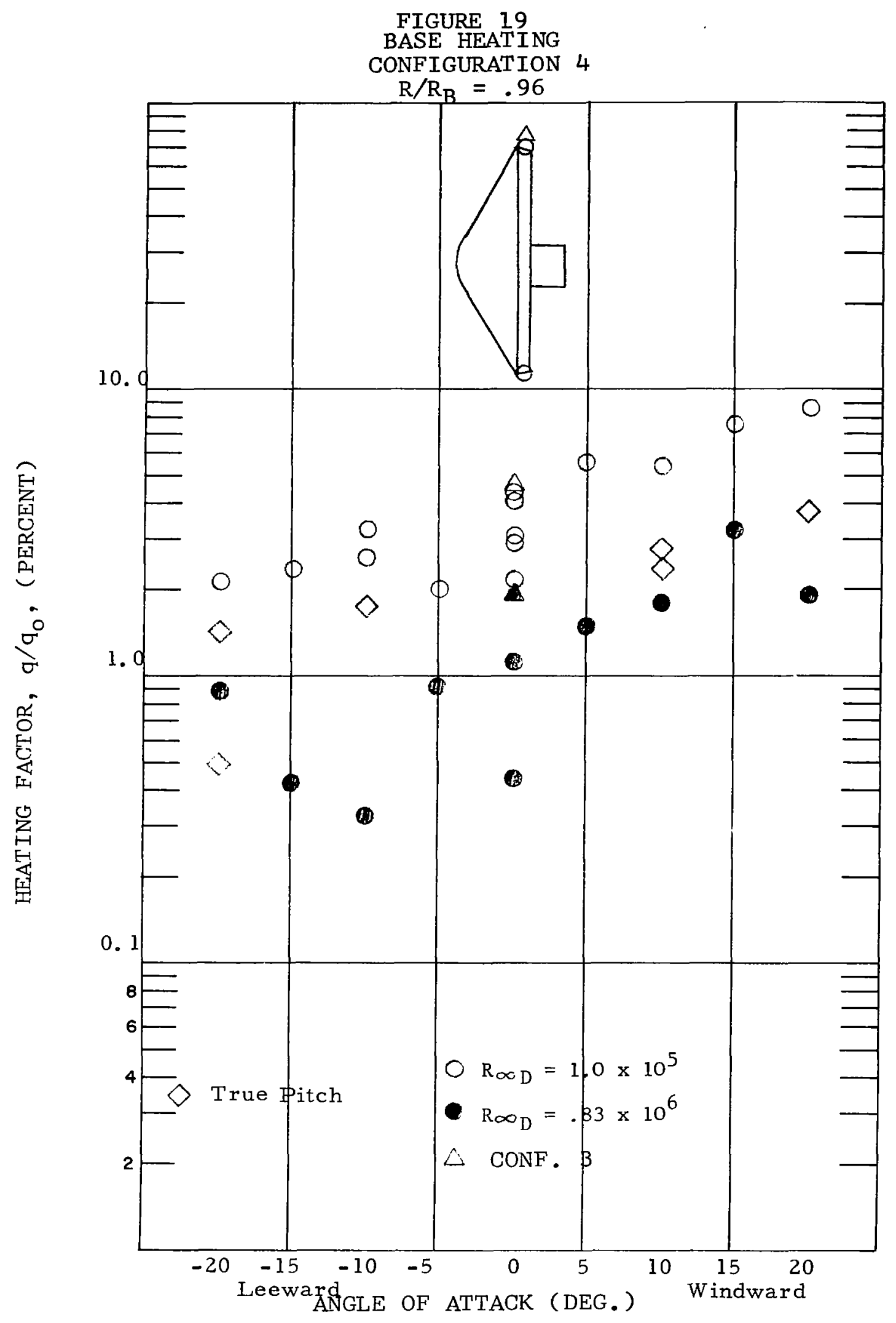




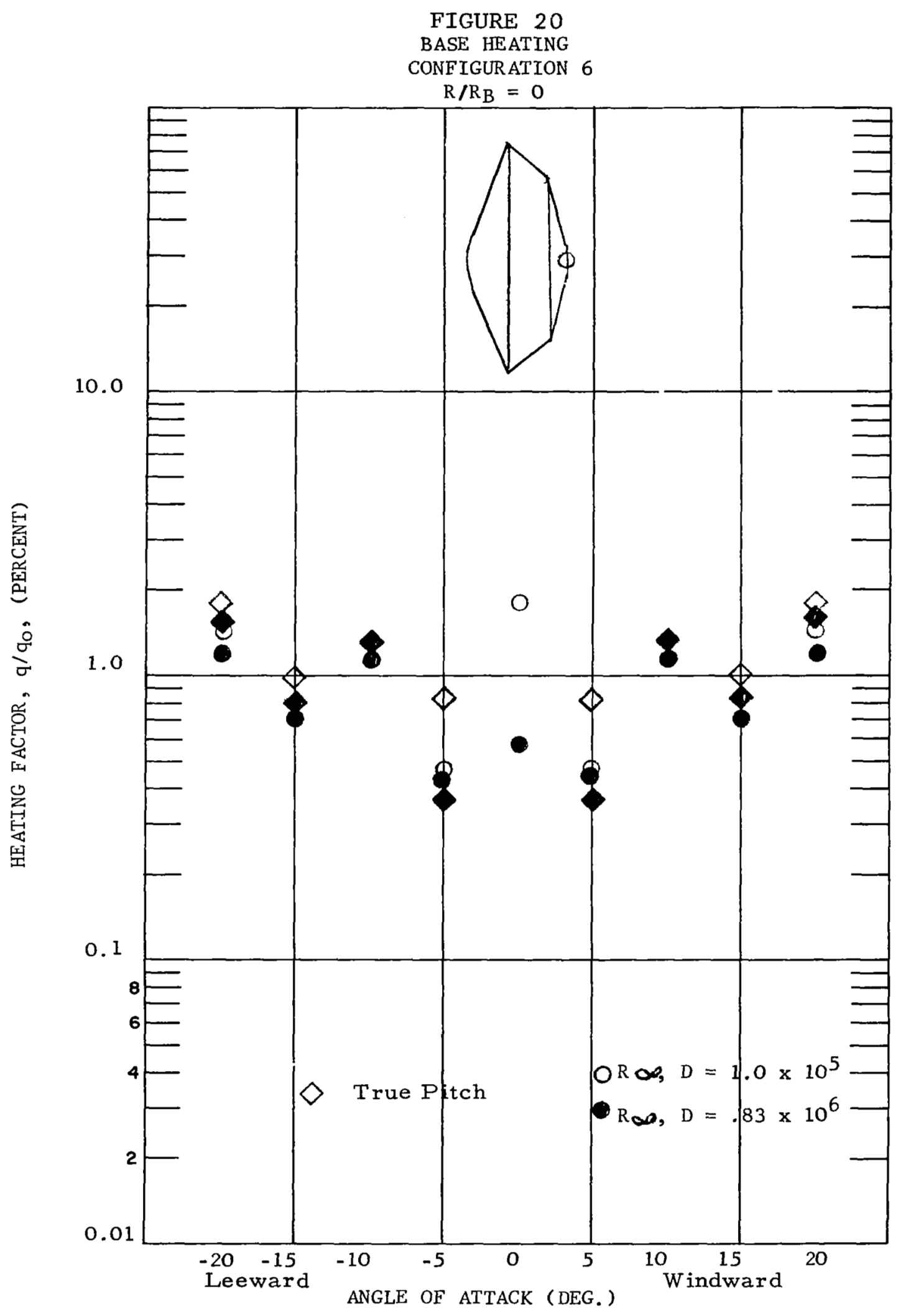




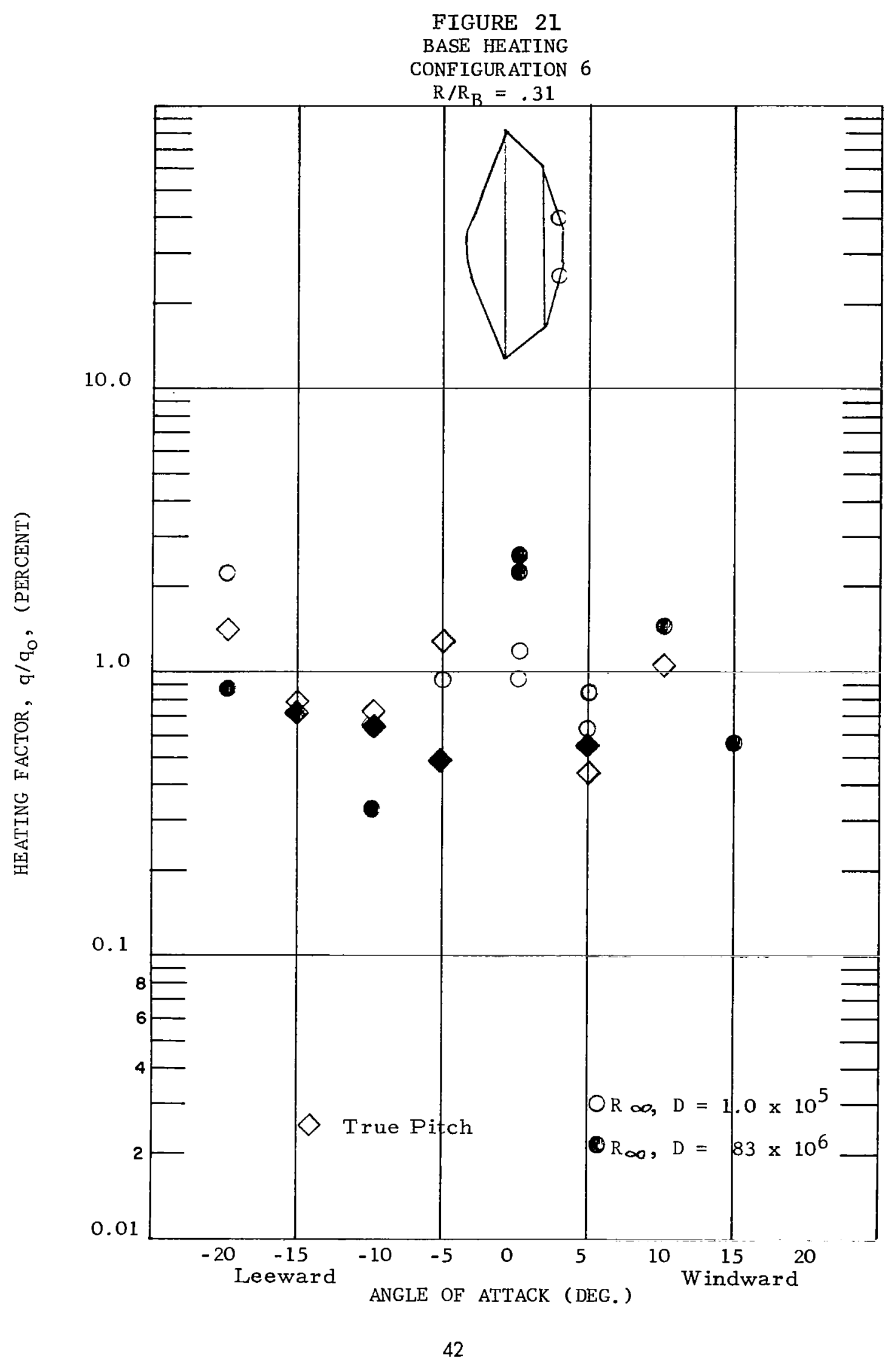




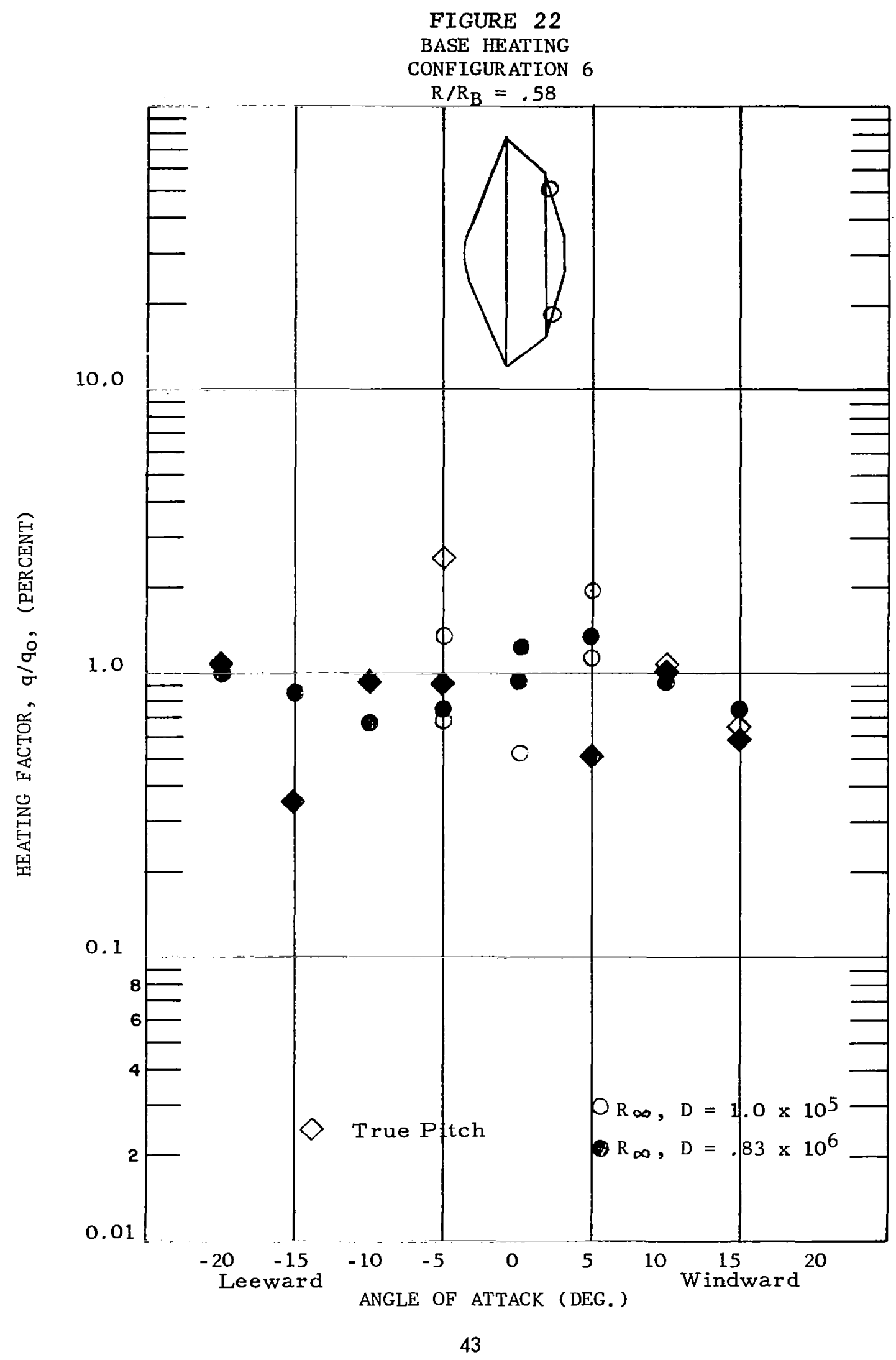




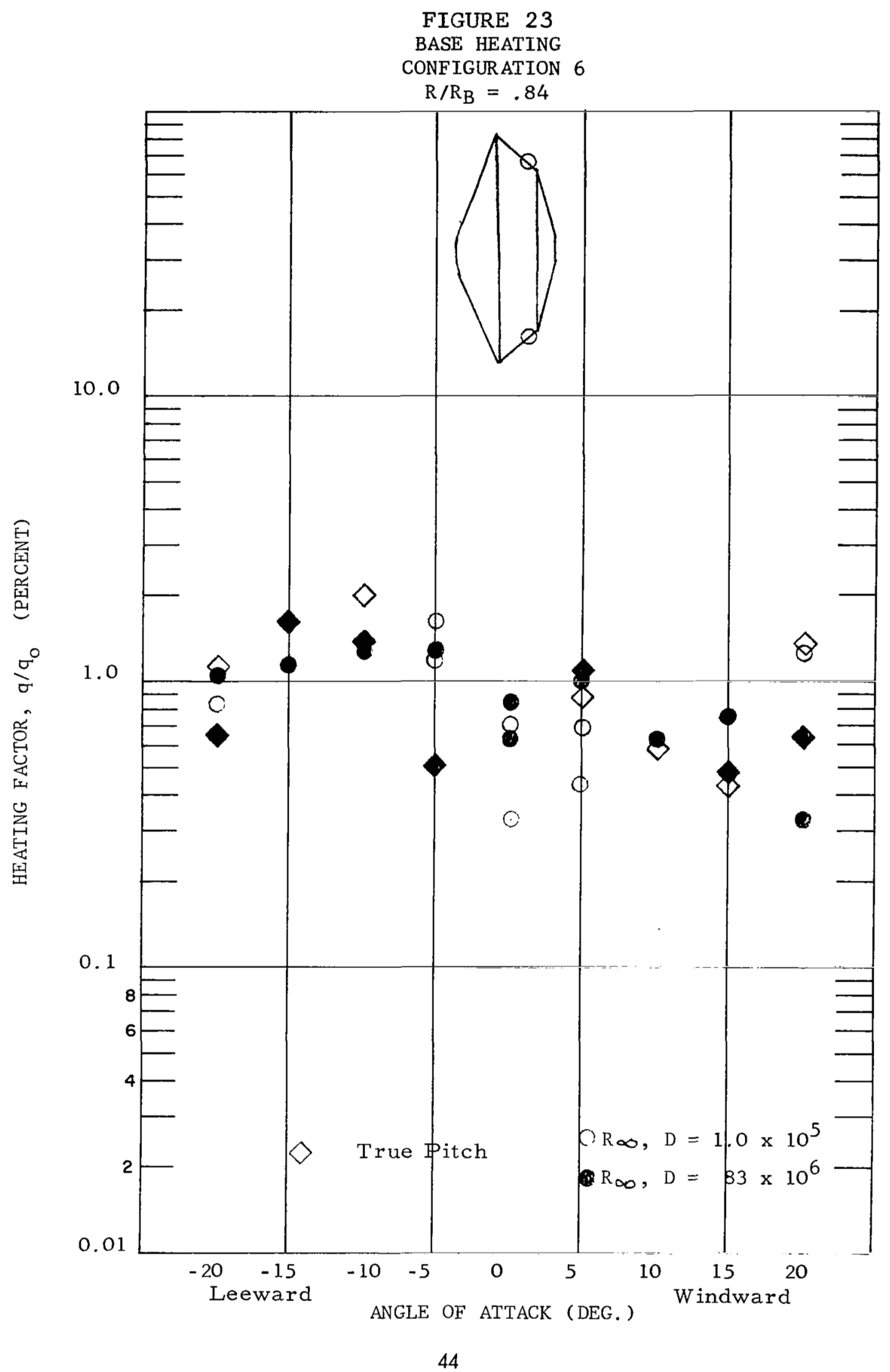




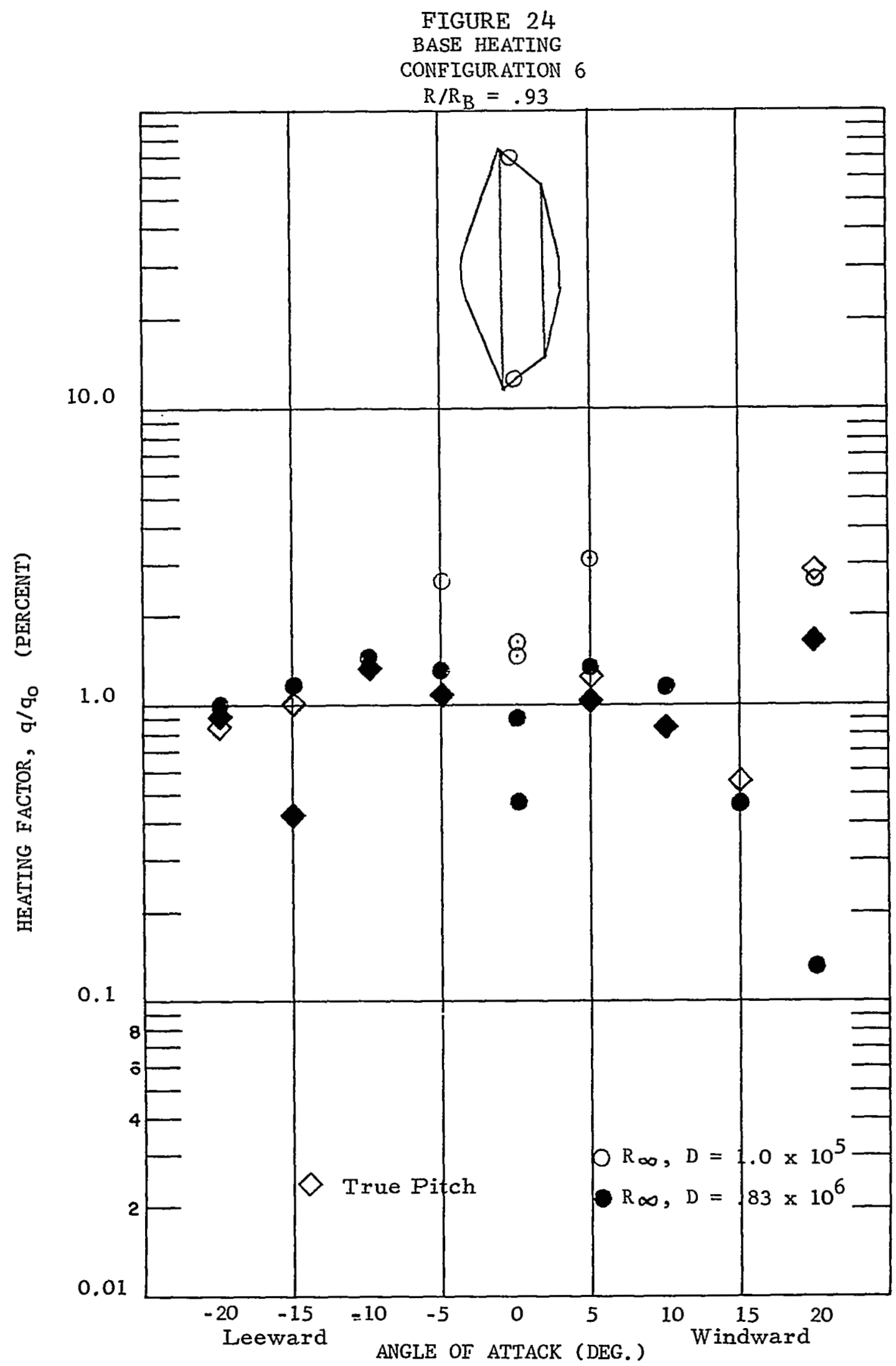




\subsection{CONCLUSIONS AND RECOMMENDATIONS}

The results of the present experimental investigation have indicated that the base heating rates are less than two percent for the Viking shape (140 degree cone) based on the reference sphere heating. The 120 degree cone base heating is slightly higher and more sensitive to Reynolds number. The use of a reference base heating results in a reduced variation in the data for variations in the Reynolds number. The average heating in the separated base region normalized with respect to the reference base heating is less than would be predicted by Chapman (Reference 16).

Afterbody heating characteristics can be categorized into the following regions: the boattail (for shallow angles, i. e., less than twenty degrees approximately), the outer separated region and the inner base region. The exact boundary between these latter two regions is not discernable.

The boattail region experiences the highest heating, and has the usual variation with angle of attack although the values measured were lower than were expected. The outer separated region experiences reduced heating on the windward side at angle of attack, whereas the inner separated region exhibited reduced heating for both the windward and the leeward side.

The variation in gas mixture resulted in base heating which was consistent with the previous air data when compared with the proper Reynolds number. Variable entropy effects were similar since the shock shapes were comparable (shock density ratios were equal).

More precise comparisons could be made for the base heating if base pressure measurements were included as part of a base heating test program. These data would also be a valuable extension of the available data with regard to base pressures. It would be of further value to measure the forebody heating, thereby eliminating the necessity for evaluating the variable entropy effects or concommitantly, confirming the methods used in its evaluation. In order to evaluate these effects for conditions similar to those experienced at flighi conditions, alternate gases should be considered (such as Freon) which would give the proper shock shape for the blunt cones of incerest.

Although the comparisons between the pitch and out of pitch plane data are in substantial agreement, additional data are desirable for the peripheral distribution, particularly for boattail regions where cross flow effects are possible. 


\section{REFERENCES}

1. Chapman, D. R., D. M. Kushn, and H. K. Larson, Investigation of Separated Flows in Supersonic and Subsonic Streams with Emphasis on the Effect of Transition, NACA Report 1356, (1958).

2. Bogdonoff, S. M. and I. E. Vas, Some Experiments on Hypersonic Separated Flows, American Rocket Society Preprint \#2172-61, (October 1961).

3. Charwat, A. F., J. N. Roos, C. F. Dewey, and J. A. Hitz, An Investigation of Separated Flows - Park 1: The Pressure Field, Journal of Aerospace Sciences, 28, (June 1961).

4. Charwat, A. F., J. N. Roos, C. F. Dewey, and J. A. Hitz, An Investigation of Separated Flows - Part II: Flow in the Cavity and Heat Transfer, Journal of Aerospace Sciences, 28, (July 1961).

5. Erdos, J., and A. Pallone, Sh ock Boundary Layer Interaction and Flow Separation, Proceedings of the 1962 Heat Transfer and Fluid Mechanics Institute.

6. Chapman, D., "An Analysis of Base Pressure at Supersonic Velocities and Comparison with Experiment," NACA Report 1051 (1951).

7. Reeves, B. I., H. Buss, and R. Weiss, "The Near Wake of Axisymmetric Bodies in Hypersonic Flow, Part I," Paper presented at the Eighteenth International Astronautical Congress, Belgrade, Yugoslavia, Sept. 24-30 (1967).

8. Weiss, R., "The Near Wake of Axisymmetric Bodies in Hypersonic Flow," Avco/Everett Res. Lab. Report AMP 251 (1967).

9. Grange, J. M., J. M. Klineberg and L. Lees, "Laminar BoundaryLayer Separation and Near-Wake Flow for a Smooth Blunt Body at Supersonic and Hypersonic Speeds," AIAA J. 5, 1089-1096 (1967).

10. Murman, E. M., C. W. Peters on and S. M. Bogdonoff, "Diagnostic Studies of Laminar Hypersonic Cone Wakes," AGARD Conference on the Fluid Physics of Hypersonic Wakes, Vol. 1, (May 1967). 
11. Reeves, B. I., and H. M. Buss, Theory of the Laminar Near Wake of Axisymmetric Slender Bodies in Hypersonic Flow. Av.co Missile Systems Division, AVMSD-0122-69-RR, February 1969.

12. Comparative Studies of Conceptual Design and Qualification Procedures for a Mars Probe/Lander, Final Report, Volume V, Bood 2, Space Systems Division, Avco Corp., AVSSD-0006-66-RR, 11 May 1966.

13. Fay, J. A. and F. R. Riddell, Theory of Stagnation Point Heat Transfer in Dissociated Air, Avco Everett Research Laboratory, Research Report No. 1, 1957.

14. Schurmann, E. E. H., Engineering Methods for the Analysis of Aerodynamic Heating (U), Avco RAD-TM-63-68 (11 November 1963). Unclassified.

15. Eckert, E. R. G., Survey on Heat Transfer at High Speeds NADC, Technical Report 54-70, April 1954.

16. Chapman, D. R., A Theoretical Analysis of Heat Transfer in Regions of Separated Flow, NACA Technical Note 3792, October 1956. 